\title{
Sentence topics in the languages of Europe and beyond
}

Elena Maslova and Giuliano Bernini

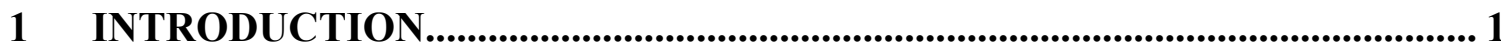

2 THE HYPOTHESIS OF EXISTENCE FOR SENTENCE TOPIC: PRO AND

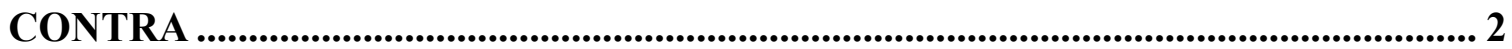

3 PHENOMENOLOGY OF SENTENCE TOPICS: AN OVERVIEW .................. 7

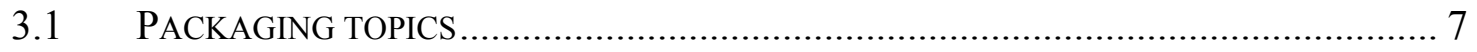

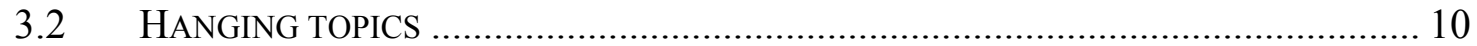

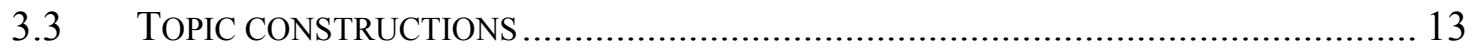

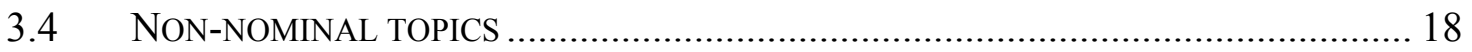

4 SEMANTIC GROUNDING OF THE TOPIC-COMMENT STRUCTURE .... 21

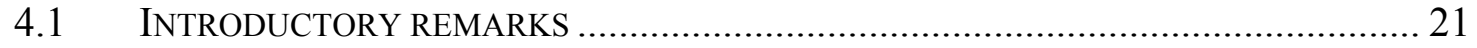

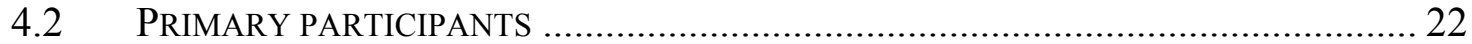

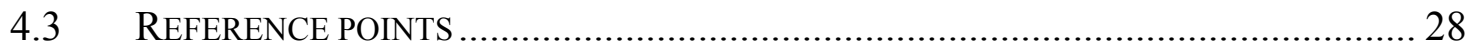

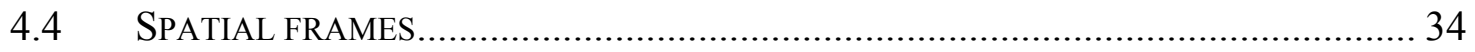

4.5 THREE SEMANTIC TEMPLATES VS. THREE ASPECTS OF TOPICALITY …………...... 38

5 LANGUAGE-INTERNAL AND CROSS-LINGUISTIC VARIATION IN

TOPIC ENCODING ................................................................................................ 42

5.1 COMPETITION BETWEEN TOPIC-ENCODING TEMPLATES..................................... 42

5.2 NEUTRALIZATION OF FORMAL DISTINCTIONS BETWEEN TOPIC-ENCODING

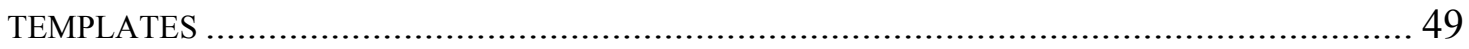

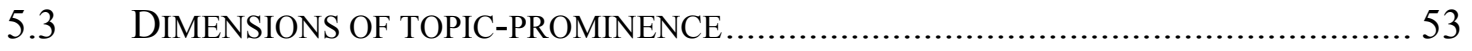

\section{Introduction}

The concept of sentence topic is one of the most controversial linguistic ideas. The reason for this seems quite clear: this concept seems too vague to be fruitfully applied to analysis of language-specific constructions, let alone cross-linguistic investigations. Yet there exists a range of "topic-related" syntactic phenomena, which provide the languageinternal motivation for this concept and apparently make it impossible to discard it altogether. The variety of these phenomena can be preliminarily illustrated by the following conversation:

(1) English

a. [inspector] "You are not to open any letters unless you recognize the handwriting," he said.

b. 'Everything else we'll look at first. 
c. As to the phone calls..."

d. [woman] "Your sergeant said you'd have an arrangement to get my phone monitored" (Ruth Rendell, No more dying then. An Inspector Wesford Mystery.)

In spite of their obvious structural and functional diversity, these constructions display some essential similarities: a referring expression is more or less explicitly opposed to the rest of the sentence and thereby excluded from the scope of assertion. In this paper, we take these similarities as the central piece of evidence in favour of the cross-linguistic relevance of the concept of sentence topic and assume, as a working hypothesis, that these and similar constructions instantiate the same universal phenomenon. Our goal is to demonstrate that this hypothesis opens the possibility to account, in unified fashion, for language-internal and cross-linguistic variation in topic encoding and for universal constraints on this variation. Section 2 discusses this hypothesis in further detail and outlines the structure of the paper. Although the paper focuses on the languages of Europe, the so-called topic-prominent languages (in Li and Thompson's (1976) sense) serve as the natural standard of comparison for any typological study of topic constructions and are therefore frequently invoked in the discussion. In addition, we draw evidence from some other languages whenever generally relevant typological options cannot be exemplified by data from European languages.

\section{The hypothesis of existence for sentence topic: pro and contra}

The most widely accepted definition of sentence topic is "what the sentence is about" (Hockett 1958: 21), or, in a more refined formulation suggested by Gundel, what "the speaker intends to increase the addressee's knowledge about, request information about, or otherwise get the addressee to act with respect to" (Gundel 1988: 210). The most obvious arguments against this definition (as well as against the linguistic validity of the concept itself) is that it is vague and provides no rigorous criteria for identification of the topic of a given sentence, at least without scrutinising a broader discourse context and/or speech situation (cf. Polinsky 1999: 572; Jacobs 2001 for recent discussions). However, the concept of sentence topic (in various terminological guises) would be employed again and again for description and explanation of certain linguistic phenomena. Informally, these are phenomena that cannot be appropriately accounted for by the apparatus of 
propositional semantics, but favour a description in terms of a context-sensitive choice of a syntactically prominent entity (=topic) that is in some sense kept outside the scope of assertion (or another illocutionary operator); Section 3 provides an overview of these phenomena, with particular reference to European languages. The paper assumes, as a working hypothesis, that there exists a universal phenomenon of sentence topic - roughly speaking, a mental status of referent(s) with respect to the information conveyed by the sentence - which manifests itself in sentences where reference to an entity (topic) is in some way structurally separated from the remainder of the sentence (comment) and is thereby excluded from the scope of assertion.

The topic-comment structure of a sentence is commonly construed not as an aspect of its meaning, but rather as an aspect of how this meaning is structured for the purpose of communicative interaction, which implies that the choice of topic is guided primarily by the speaker's assumptions about the listener's state of knowledge. This view is perhaps most picturesquely expressed in Chafe's metaphor comparing topics and other discourse-sensitive statuses with the packaging of toothpaste (1976: 28): the toothpaste exists and remains essentially the same independently of whether or not it is packaged, yet it has to be packaged to be delivered to the customers and conveniently used as intended. Similarly, the meaning of a sentence exists (in the mind of the speaker) independently of whether or not it is packed into a certain topic-comment structure, but it has to be "packaged" in an appropriate way to be conveniently processed and properly understood by the listener. Morphosyntactic phenomena providing evidence for this view are overviewed in Section 3.1. However, the analysis of the full range of topic-comment sentences demonstrates that the hypothesized topic status must belong to the meaning conveyed by the sentence, rather than just being an aspect of "packaging" of this meaning (see Sections 3.2-3.3). In Section 4 we argue, in fact, for a stronger version of this view, namely, that the topic status is grounded in the perception/construal of reality: it is not only about structuring information for the purpose of being communicated and processed, but also about the structure of perceptions and thoughts.

The central piece of evidence against unified approach to sentence topic is the existence of multiple "topic constructions" with different functions both within a single language and across languages (cf., for example, the distinction between "topic" and 
"theme" in Functional Grammar (Dik 1989; Bolkestein 1993: 345-346); see also Jacobs' (2001) for elaborate argumentation to this effect). To begin with, the existence of topicality as a universal category - as a mental status of an entity with respect to the information conveyed by the sentence - must not (and in fact hardly can) entail the existence of a uniform topic encoding in each and every language. More or less significant differences between functionally similar constructions competing within a single language is what keeps happening again and again in all domains of grammar, and thus what we would expect of topic-encoding constructions as well. The genuine problem with identification of topic-encoding constructions - and more generally, with the hypothesis of existence of topic in general - is, to put the things plainly, that there are obviously no topics in the "real world". The topic status - assuming it indeed exists - is a language-internal, or, in slightly more cautious wording, mind-internal phenomenon without obvious counterparts in the perceived reality. It is apparently for this reason that the co-existence of alternative topic-encoding constructions in some (or even most) languages can be perceived as evidence against the existence/reality of topic status, in contrast to linguistic categories more obviously grounded in (our perception of) reality (like tense, semantic roles, etc.), for which the availability of different coding options within a single language, as well as cross-linguistic semantic differences, are easily accommodated by linguistic theories. For instance, our belief in the existence of time is firmly grounded in our perception of reality and cannot be shaken by language-internal and cross-linguistic variation in its grammatical encoding. With topics, it is obviously not the case. However, if the topichood is recognized as an aspect of meaning, the existence of alternative topic-encoding options and the functional differences between topic constructions within and across languages cannot be plausibly construed as evidence against the existence of this meaning, since essentially similar variation in coding options exists for any other aspect of meaning.

However, the lack of obvious "real world" counterparts of topics means that our understanding of what the topic status of a referent actually "means" (i.e. what it contributes to the meaning of the sentence) can only be based on the analysis of functions of language-specific topic constructions, at least until the neural studies of human brain are developed enough to provide independent evidence. The only palpable common 
property of all topic constructions is that they allow the speakers to activate a referent without including it into the scope of assertion (or another illocutionary operator), i.e. to separate reference to an entity from the act of assertion. The only thing this can tell us about the hypothesized mental status of topic is that if an entity has this status with respect to a piece of information, then activation of its mental representation is essential for interpretation of this information but is not (or need not be) a component of this piece of information (more precisely, of the proposition encoding this piece of information). However, different structural types of topic constructions have been described in terms of specific relations established between the topic and its comment: apart from (i) the "aboutness" topic function, the functions ascribed to topics include (ii) delimiting the frame within which the main predication holds (Chafe 1976: 50; Li \& Thompson 1976; Jacobs 2001) and (iii) anchoring the predication in the context, thus linking it to the listener's presumed state of knowledge (Mathesius 1929; Chafe 1976, 1987; Prince 1981; Gundel 1988; inter alia). In what follows, we refer to these three aspects of topicality as $\alpha$-topic, $\sigma$-topic and $\rho$-topic respectively. It seem worth noting at this point that Strawson's (1964) characterisation of the relation of aboutness, in effect, invokes $\sigma$-topic and $\rho$-topic functions: if the listener cannot identify ( $\rho$-topic) the referent of $\alpha$-topic, he is unable to evaluate the main predication as true or false ( $\sigma$-topic). The hypothesis of semantic grounding of topicality developed in Section 4 suggests that all aspects of topicality are in fact relevant for all types of topic constructions, i.e. the hypothesized mental status in some sense invokes all three relations between an entity and a predication. We assume, however, that the intuitive notion of "aboutness" ( $\alpha$-topic) is as close to the hypothesized mental status of topic as reasonably possible at the present state of knowledge and will occasionally invoke the aboutness-based intuitions in the following discussion, without attempting to define "aboutness" in more explicit and rigorous terms. ${ }^{1}$

${ }^{1}$ In our view, the topic status cannot be reduced to semantic predication (cf. Jacobs 1999, Kiss 2003), since this would, by definition, exclude hanging-topic sentences (Section 3.2). The explication of aboutness in terms of "mental addressation" (Reinhart 1982; Vallduví 1995: 123-125; Jacobs 2001) seems to be based on overly simplistic and 
Although the $\rho$-topic function is an inherent aspect of the hypothesized phenomenon of topic, language-specific topic constructions can impose different constraints on the assumed degree of activation of the topic referent in the listener's mind by the time of utterance (Chafe 1976, 1987; Prince 1981; Geluykens 1989, 1992; Lambrecht 1994: 77-113; inter alia). Cross-linguistically, such constraints correlate, to a certain degree, with structural properties of topic constructions; for example, leftdislocations tend to be associated with a relatively low degree of activation. However, the language-internal and cross-linguistic variation in the degree of activation of topic referents for different topic constructions and, more broadly, in the ranges of discourse contexts in which these constructions are felicitous pose problems for the unified approach to sentence topic only if this concept itself is construed as a purely packaging phenomenon. The approach advocated here presupposes a distinction between the topiccomment structure as an aspect of the meaning to be conveyed, on the one hand, and the way this meaning is expressed, on the other. Whether and how the topicality of a referent is encoded is expected to depend on the listener's assumed state of knowledge and attention, as well as on the salience of the topic-comment structure in the overall meaning of the sentence. In this respect, topicality does not differ from any other not fully grammaticalized meaning: the fact that the way a meaning is encoded depends on the context cannot and does not entail that different contexts correspond to different meanings. In Section 5, we demonstrate that a consistent distinction between the concept of sentence topic and language-specific constructions that can express this meaning allows for a unified explanation of language-internal and cross-linguistic variation in context-sensitive constraints associated with different topic constructions, on the one hand, and for attested constraints on such variation, on the other.

"metaphorical" model of human memory and, in fact, does not provide any more explicit criteria for identification of topics than the intuitive notion of "aboutness". 


\section{Phenomenology of sentence topics: an overview}

\subsection{Packaging topics}

The first class of topic-related structural phenomena can be described in terms of "packaging variants" (Chafe 1976: 28) of the same contents: a sentence token consisting of a referring expression and an assertion is paradigmatically opposed to one or more propositionally equivalent sentences which would organize the same propositional contents in a different way, i.e. single out another referring expression or none at all. The following examples from Russian illustrate some characteristic paradigmatic oppositions of this type (sentences (a) are authentic examples from Russian texts, (b) represent alternative packaging options).

Voice oppositions:

(2) Russian $^{2}$

a. Ves' nižnij etaž tëtkin-ogo dom-a byl whole ground floor aunt:POSS-GEN house-GEN was zanjat restoran-om occupied:M.SG restaurant-INST 'The whole ground floor of the aunt's house was occupied by a restaurant.' (Mixail Bulgakov, "Master i Margarita")

b. Restoran zanima-l ves' nižnij etaž tëtkin-ogo restauran occupy-PST.SG.M whole ground floor aunt:POSS-GEN dom- $a$ house-GEN

'The restaurant occupied the whole ground floor of the aunt's house.'

2 Although this paper is primarily based on a corpus of authentic example sentences excerpted from natural discourse, at some points we have to resort to constructed examples in order to illustrate paradigmatic oppositions available in different languages. This includes some examples borrowed from linguistic literature (linguistic sources are indicated before the example sentence). References to primary sources (newspapers, Internet chats, fiction, etc.) are given in brackets after idiomatic translations. If the source is not explicitly indicated, the example (from Russian or Italian) is constructed on the basis of the native language competence of one of the authors. 
Linear order:

(3) Russian

a. Takuju že illjustrativn-uju funkcij-u imej-ut

such same illustrutive-ACC function-ACC have-PRES.3PL

sxem-y R.Van Valin-a i W.Foley

scheme-PL.NOM R.Van Valin-GEN and W.Foley

'The same illustrative role is played by R. Van Valin and W. Foley's schemes.' (Aleksandr Kibrik)

b. Sxem-y R.Van Valin-a i W.Foley imej-ut

scheme-PL.NOM R.Van Valin-GEN and W.Foley have-PRES.3PL

takuju že illjustrativn-uju funkcij-u

such-ACC same illustrutive-ACC function-ACC

'R. Van Valin and W. Foley's schemes have the same illustrative function.'

Dislocation:

(4) Russian

a. Postojannoe vnimanie $k$ kul'tur-e mal-yx nacional'nost-ej

permanent attention to culture-DAT small-GEN ethnicity-PL.GEN

eto-mu nas uč-it otec

this-DAT us.ACC teach-PRES.3SG father

'Permanent attention to the the culture of national minorities, that's what

Father teaches us.' (Semyon Lipkin, "Dekada")

b. Otec uč-it nas postojann-omu vnimanij-u

father teach-PRES.3SG us.ACC permanent-DAT attention-DAT

$k$ kul'tur-e mal-yx nacional'nost-ej

to culture-DAT small-GEN ethnicity-PL.GEN

'Father teaches us (to pay) permanent attention to the culture of national minorities.'

The following examples illustrate similar sub-paradigms of packaging variants from other European languages:

(5) English (Foley \& Van Valin 1985: 299)

a. The man was kissed by the woman.

b. The woman kissed the man.

(6) Hungarian (É. Kiss 1995b: 208-209)

a. Évát János várta a mozi előtt

Eve.ACC John waited the cinema in.front.of

'Eve was waited for in front of the cinema by John.'

b. János Évát várta a mozi előtt

John Eve-ACC waited the cinema in.front.of 
'John waited for Eve in front of the cinema'

(7) German (Jacobs 2001: 642)

a. Peter, ich habe ihn heute nicht getroffen. P. I PFV.1SG he.ACC today NEG meet:PST.PART 'Peter, I have not met him today.'

b. Ich habe Peter heute nicht getroffen.

I PFV.1SG P. today NEG meet:PST.PART 'I have not met Peter today.'

In these and similar examples the structural differences between paradigmatic alternatives can be described in terms of singling out one component of the main proposition by putting it into a syntactically prominent position, which is syntagmatically opposed to the rest of the sentence (the subject position in (2) and (5), the clause-initial position in (3) and (6), and the clause-external "topic" position in (4) and (7)), the approach most broadly applied in discussions of topic-comment structures.

Whereas the very existence of packaging variants demonstrates a certain degree of independence between the topic-comment structuring and the propositional arrangement of information, yet the relation between these structures is constrained insofar as the "packaging" topic expression always specifies a variable in the propositional structure of the message (although not necessarily an argument variable of the main predicate). Indeed, it is this constraint that guarantees that alternative packaging variants with exactly identical propositional contents are possible at all (that is, that the topic expression can be present in a sentence with the same propositional contents in a non-topical structural position). Moreover, many language-specific constructions that ensure availability of alternative packaging variants impose further constraints on the relationship between the topic-comment structure and the propositional structure (most obviously, this concerns voice constructions).

The existence of topic-oriented "packaging variants" with the same propositional contents gives one of the most important pieces of evidence in favour of the hypothesis of sentence topic and seems to indicate that the topic status resides not in the "contents" to be communicated (it apparently remains constant independently of which entity is chosen as the topic), but in the way this contents is encoded for the purpose of communication (i.e. for transmission of the information to the listener). In this sense, it is similar to other 
"packaging statuses" or "pragmatic roles" of NPs (e.g., to the role of narrow focus). According to this view, an entity would assume the topic status only in the context of speaker-hearer interaction: it is a part of how the speaker "packages" the semantic contents for the listener and the choice of topic is thus guided primarily by the speaker's assumptions about the listener's state of knowledge (Chafe 1976, 1987; Prince 1981; Gundel 1988; inter alia).

\subsection{Hanging topics}

The second class of topic-related phenomena comprises so-called "hanging" topics, i.e. sentences in which the topic expression is juxtaposed to a clause-like component denoting the main proposition, and does not specify a variable of this proposition; in other words, the semantic ("real-world") relation between the topic and the state of affairs described by the comment is not linguistically encoded and thus does not belong to the propositional structure of the sentence.

This class of sentences received particular attention in linguistic typology due to so called "topic-prominent" languages ( $\mathrm{Li}$ and Thompson 1976), where this way of organizing sentences is fully conventionalised; the topic expression either bears an overt morphosyntactic topic marker (an adposition (8) or an affix (9)), or remains unmarked, as in (10).

(8) Japanese (Chen 1996: 402)

Nihon wa syuto ga sumi-yo-i

Japan TOP capital NOM live-good-PRS

'As for Japan, its capital is a good place to leave.'

(9) Korean (Li and Thompson 1976: 468)

Pihengi-nin 747-ka khi-ta

Airplane-TOP 747-SBJ big-STAT

'Airplanes, the 747 is big.'

(10) Chinese (Chen 1996: 402)

haixian, wo zui ai chi longxia

seafood I most love eat lobster

'As for seafood, I like lobster most.' 
Sentences with unmarked hanging topics appear to occur (at least) in informal registers of all languages, even if they are not fully conventionalised and are therefore avoided or even prohibited in more formal registers; the availability of this structure probably constitutes a universal property of "unplanned discourse" (Gundel 1988: 238-239); at least, whenever this sort of data is scrupulously investigated, some instances of hanging topics are likely to be found. The following examples illustrate this phenomenon for some European languages:

(11) Italian (field notes)

[looking at the fruit (casual conversation)]
La frutta- $t$ ' DEF fruit 2SG.OBJ.CLT help.yourself:IMP
'[If you like] fruit, help yourself.'

(12) Russian (Miller 1992: 96)

$\begin{array}{llll}\begin{array}{l}\text { Sobak-a } \\ \text { dog-NOM.SG }\end{array} & \begin{array}{l}\text { vsegda } \\ \text { always }\end{array} & \text { floor-PL } & \text { grjazn-ye } \\ \text { dirty-PL }\end{array}$

'The/a dog, the floors are always dirty.'

(13) English (Lambrecht 1994: 193)

[a sentence produced by a lecturer in an introductory linguistic course]

Other languages, you don't just have straight tones like that.

On the other hand, all European languages seem to have more or less conventionalised expressions that can be used to introduce topics without integrating them into the proposition; a list of such expressions from a number of languages is given in (14).

(14) Topic-introducing expressions in European languages:

Italian Per quanto riguarda $T$ for what concerns $\mathrm{T}$

English as for/to $T$

as regards/concerns $T$

$\begin{array}{lll}\text { German } & \text { was T angeht/betrifft } & \text { what T concerns } \\ \text { Dutch } & \text { wat T betreft } & \text { what T concerns } \\ \text { Swedish } & \text { Pa0 tal om } T & \text { On mention about T } \\ & \text { ifra0ga om } T & \text { in question about T } \\ \text { Russian } & \text { Čto do } T & \text { what to T(GEN) } \\ & \text { Čto kasaetsja T } & \text { what touches T(GEN) } \\ \text { Hungarian } & \text { T-val/vel kapcsolat-ban } & \text { X-COM relation-LOC } \\ & \text { Tilletö-en } & \text { T(ACC) regarding-ADV }\end{array}$


Whereas formally the topic expressions are integrated into the propositional structure by means of a relational expression (including verbs with meanings like concern, touch, regard, etc.), the actual semantic relation between the topic and the state of affairs described in the comment is not encoded, so in this sense the topics are "hanging", e.g.:

(15) German (Jacobs 2001: 654)

$\begin{array}{lcllll}\text { Was Goethes 250. } & \text { Geburtstag } & \text { betrifft: } & \text { Das } & \text { Stadttheater } \\ \text { what G. } & 250 & \text { birthday } & \text { concern.3SG DEF } & \text { municipal.theater } \\ \text { plant } & \text { eine } & \text { ungekürzte } & \text { Faust-Aufführung. } & \\ \text { plan.3SG } & \text { INDF } & \text { unabridged } & \text { Faust-performance } & \end{array}$

'As for Goethe's $\mathbf{2 5 0}^{\text {th }}$ birthday, the municipal theater plans an unabridged performance of "Faust".'

(16) Russian (from Internet chats)

a. Čto kasaetsja professional'n-oj terminologi-i, to ja sovsem what touches professional-GEN terminology-GEN, then I completely prevraščjajus' $\quad v$ inostrank-u turn.into.PRES.1SG in foreigner-F.DAT

'As for work-related terminology, I am turning into a complete foreigner.'

b. Čto že do praktičesk-ogo programmirovani-ja-sprosite

what PRT to applied-GEN programming-GEN ask(IMP:2PL) ešče, a javljaetsja li nauk-oj slesarnoje delo also CNJ constitutes INTR science-INST locksmith:ADJ profession 'As for software engineering, you can as well ask whether locksmithing is a science.'

(17) Catalan (Vallduví 1995: 90)

Quant al Joan $i$ la Isidora no t'ho sé dir

As.for the J. and the I. no IO.O know.1SG say

doncs el Joan el veiem ben poc

since the Joan OBJ 1PL.see quite little

'As for Joan and Isidora, I can't say, since Joan we see very little of.'

In sentences of this class, the topic expression cannot be taken as something "singled out" from the main proposition, since it does not refer to any of its elements to begin with: if not for being in the topic position, it would have been just absent from the sentence. In other words, the exact semantic contents of a sentence with a hanging topic cannot be expressed in any other way: this would require integrating the topic expression into the proposition, which, if possible, would involve some specification of the semantic relation between the topic and the situation being described and thus inevitably modify the 
propositional contents of a sentence in more or less significant way. This entails that hanging-topic sentences cannot be adequately described in terms of "packaging variants" of independently existing semantic contents. It follows that the topic status cannot be viewed as an aspect of "packaging" of pre-existing propositional contents. Rather, it must be a component of information/thought to be communicated; in other words, an entity assumes the topic status not after the propositional contents to be communicated is "created" (in the mind of the speaker), but rather before or in the course of the process of its creation (Kasevič 1988: 238-240). ${ }^{3}$ In this respect, the phenomenon of topic saliently differs from that of focus: there seem to be no "hanging" foci in natural languages; in other words, a reference to an entity can be included into the scope of assertion of a sentence only if it constitutes a component of its propositional structure.

\subsection{Topic constructions}

The central piece of evidence in favour of the hypothesis that hanging and packaging topic manifest the same phenomenon comes from the fact that they often instantiate the same language-specific construction. In topic-prominent languages, the construction used to introduce hanging topics also functions as the major strategy of singling out elements of the main proposition. In the following set of Japanese examples, the construction with postposition wa singles out packaging topics in the first two sentences and introduces a hanging topic in the last one.

Japanese (Shibatani 1990: 262, 275)

(18)a. Hi wa nobor-u sun TOP rise-PRS

'The sun rises.'

b. Hanako wa Taroo ga eigo o osieteita Hanako TOP Taro NOM English ACC teaching:PST 'Hanako, Taro was teaching English (to her).'

c. Tori wa mesu ga tamago o umu bird TOP female NOM egg ACC lay

'A bird, a female lays eggs.'

${ }^{3}$ A similar view seems to be reflected in the traditional logical distinction between thetic and categorical judgments (see Sasse (this volume) for an overview). 
In European languages, the topic-introducing expressions like in (14) are certainly not constrained in terms of the relation between the topic expression and the main proposition; along with hanging-topic sentences, they can as well be used for singling out elements of the main proposition, which are then cross-referenced within the comment. This is illustrated by the following examples:

(19) Irish (Ó Siadhail 1988: 196/256)

Ach maidir le fiaclóirí na cathrach seo, nó fiaclóirí

But as to dentists ART:GEN.F city:GEN this or dentists na héireann, ni dhéanfainn aon mhuinín as-tu.

ART:GEN.F Ireland:GEN NEG do:COND:1SG one trust from-3PL

'But as far as the dentists of this city or the dentists of Ireland are concerned, I would not trust them!'

(20) Italian

Per quanto riguardava la rivoltella, di sicuro Enzo

for what concerned the revolver:SG.F of sure E.

l' aveva ereditata.

CLT.ACC:3SG.F had:3SG inherited

'As for the revolver, Enzo had certainly inherited it.' (field notes)

(21) Russian

Čto do ošibk-i, to Efremov sam pišet o nej v

what to error-GEN then E. RFL writes about 3SG.OBL in

predislovii $k$ svoemu sobraniju sočinenij

introduction:OBL to RFL.POSS:DAT collection:DAT works:GEN

'As for the error, Efremov writes about it himself in the introduction to his collected works.' (from an Internet chat)

The same is true for constructions with unmarked clause-external topics, cf. (11)-(13) and (22)-(27)

(22) Spanish (Downing 1997: 139)

La radio no la suelo escuchar

DEF radio NEG it tend(1SG) listen.to

'The radio, I don't usually listen to it.'

(23) Italian (TV advertising spot: a cartoon appears on the screen, showing a teeth arc and a scalpel removing the tartar from it. An off-screen voice says:)

Il tartaro il dentista lo toglie 
the tartar.SG.M the dentist CLT.ACC.3SG.M removes

ma poi si riforma

but then RFL forms.again

'The dentist removes the tartar, but it comes back again'

(24) Italian (Benincà et al. 1988: 132).

Noi altre monache, ci piace di sentir le storie per minuto we others nuns us delights of hear:INF the stories for trivial.detail "As for nuns as we are, we enjoy hearing stories with their trivial details" (Alessandro Manzoni, Promessi Sposi, IX)

(25) Russian (Fici Giusti-Gebert-Signorini 1991: 321)

Ta, kotor-aja zdes' stojal-a lamp-a, that:NOM.F.SG which-NOM.F.SG here stood-F.SG lamp-NOM.F.SG ja eje ne bral I 3SG.F.ACC NEG took (M.SG)

'The lamp that used to stand here, I didn't take it.' (from a recording of oral speech)

(26) English (Miller 1992: 95)

The driver, you get a good laugh with him

(27) French (Cadiot 1992: 63)

Les enfants $j^{\prime}$ leur pardonne tout

the children I.CLT them.CLT forgive:1SG all

'The children, I forgive them everything'

More generally, if a language-specific construction can be used for introducing a hanging topic, it can as well be used for singling out packaging topics; it simply does not impose any constraints on the role of topic in the proposition (or the existence thereof). Thus, insofar as hanging-topic sentences can be assumed to be a universal phenomenon, so can the sentence structure that combines a reference to an entity (topic expression) and a predicated proposition (comment) independently of whether or not the topic expression is integrated into the proposition, or, in other words, whether the semantic ("real-world") relation between the topic and the situation described by the proposition is encoded linguistically. The status of such structures as "constructions" - insofar as this term implies some degree of conventionalisation - may be controversial in some languages. It can be hypothesized, however, that both structures with unmarked clause-external topic expressions and structures with topic expressions introduced by lexically transparent expressions like in (14) belong to the stock of what Harris and Campbell call 
"exploratory expressions" (1995: 54-56, 72-75), i.e. to the structures that, if not yet conventionalised, are still universally available and can be "pushed" (by circumstances) towards conventionalisation at any time. Constructions of this class will be referred to below as $h$-topic constructions (where $h$ stands for "hanging”).

To sum up the discussion so far, the cross-linguistic availability of $h$-topic constructions and their ability to serve as a uniform topic encoding in topic-prominent languages constitutes a crucial piece of evidence in favour of the hypothesis of existence of sentence topic, whereas the existence of hanging topic sentences demonstrates that the hypothesized mental status of topic cannot be adequately described in terms of "packaging", but should be treated as an aspect of meaning conveyed by the sentence. On the other hand, many languages (in particular, the languages of Europe) have multiple topic constructions, some of which are constrained to packaging topics, or to a subset thereof (e.g. only to certain (types of) arguments of the main proposition). Such constructions fall in two major classes. In one class of constructions, the topic expression bears the same marking of its role in the propositional structure as in those packaging variants where the propositionally identical element is inside the scope of assertion; the topic encoding amounts to linear and/or intonational separation of the topic expression and the comment ( $f$-topic constructions, where $f$ stands for fronting); $f$-topic constructions are exemplified in (3) and (6) above. The second class subsumes so-called relationchanging constructions, or, more broadly, subject-predicate constructions (s-topic constructions; see (2) and (5)). ${ }^{4}$ The existence of such constructions - along with $h$-topic constructions - entails that some components of the propositional structure can be encoded as topics in two or more different ways; for example, the Russian sentence in (25) can be paraphrased as in (28), whereby both the propositional contents and (presumably) the topic-comment structure of the original example are retained:

(28) Russian

${ }^{4}$ This classification does not imply that all language-specific topic constructions neatly fall in one or another class (see Section Error! Reference source not found. for further discussion). 


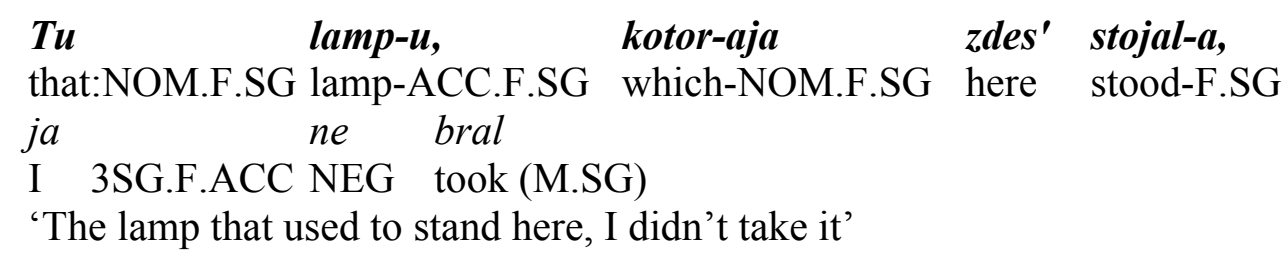

This is an instance of $f$-topic construction: the only topic-indicating device is the (objectinitial) linear order: the topic expression gets the case form determined by its role in the main proposition, and the comment contains no pronouns cross-referencing the topic. In Russian, then, the $h$-topic construction "competes" with the $f$-topic construction for encoding of packaging topics. The $f$-topic construction is considerably more conventionalised - whereas (25) is clearly perceived as resulting from the lack of "planning" and is only acceptable in informal colloquial speech, (28) is unmarked in this respect. The following pair of examples illustrates a similar competition between the $h$ topic construction and the $s$-topic construction:

(29) Russian

a. Politkorrektnost' ee vzroslyje izobre-li

Political.correctness it:ACC adults:PL.NOM invent-PST.PL

[Children bully one another everywhere.] 'Political correctness, adults have invented it.' (from an Internet chat)

b. Politkorrektnost' izobretena vzrosl-ymi

Political.correctness invent:PASS adults-PL.INST

'Political correctness has been invented by adults.'

Clearly, whenever alternative topic constructions are available, their functions are bound to differ to some extent. Apart from the register-based constraints, a specific construction can be constrained in terms of the role of the topic expression in the propositional structure of the sentence: in Russian, for example, the $s$-construction (as in (29b)) is available only for (a subset of) core arguments of the main verb: for other topics, the range of available coding options is limited to $h$-constructions and $f$-constructions.

On the other hand, topic constructions can be associated with different types of discourse contexts; in particular, they can impose different constraints on identifiability and activation of the topic referent (Chafe 1976, 1987; Gundel et al. 1993; inter alia)). As preliminarily discussed in Section 2, this variation does not contradict the hypothesis of 
existence for sentence topic, insofar as topicality is thought of as a component of meaning, rather than an aspect of how this meaning is packaged for the purpose of communication. On the contrary, this hypothesis predicts the existence of alternative coding options and allows for a unified account of the attested constraints on languageinternal and cross-linguistic variation of topic encoding. We return to this question in Section 5.

\subsection{Non-nominal topics}

In the body of this paper (Sections 4-5), we focus on the conceptually simplest and most common type of topic-comment sentences, where the topic referent is a stable entity referred to by a nominal expression and the comment is a description of a state of affairs. However, the hypothesis of existence for sentence topic does not rule out that this mental status can be assigned to a state of affairs, as in the following examples: ${ }^{5}$

(30) Italian (Benincà et al. 1988: 189)
a. Che si parta tutti insieme, that IMPR leave:SBJ:3SG all soluzione solution together NEG is a nice

'That we should leave all together isn't a good solution'
b. Che arrivavate oggi, non me l'aveva detto nessuno that arrive:IMPF:2PL today NEG to.me it.had:3SG told nobody 'Nobody had told me that you would arrive today'

The ability of predicates to serve as topic expressions is more problematic, since they do not refer (cf. Lambrecht 1994: 76); accordingly, it is unclear what exactly can be thought

\footnotetext{
${ }^{5}$ According to Lötscher (1992), adverbs can also be topics, as in Finanziell ist Otto sehr erfolgreich 'Financially, Otto is very successful' (p. 129). The suggestion is plausible, since the adverb finanziell in the example quoted here may be paraphrased as 'Was die Finanzen angeht'/'As to the financial side' etc. Our hypothesis does not preclude the possibility that the topic can be activated by means of an adverbial expression (see, in particular, Section 4.4), although the interpretation of adverbials as genuine topics can be controversial (Shibatani 1990: 275-278, Jacobs 2001: 656-657).
} 
of as the topic of such sentences. It seems, however, that the lexical predicate of the main predication in the topic position can activate a referent, namely, the state of affairs being described, whereby the statement conveyed by the comment is reduced to modality, most often, simple assertion or negation. This is possible if all relevant partipants of the state of affairs being described are recoverable from the context, so that the predicate (in an infinitival form) suffices to activate its mental representation. Consider the following example:

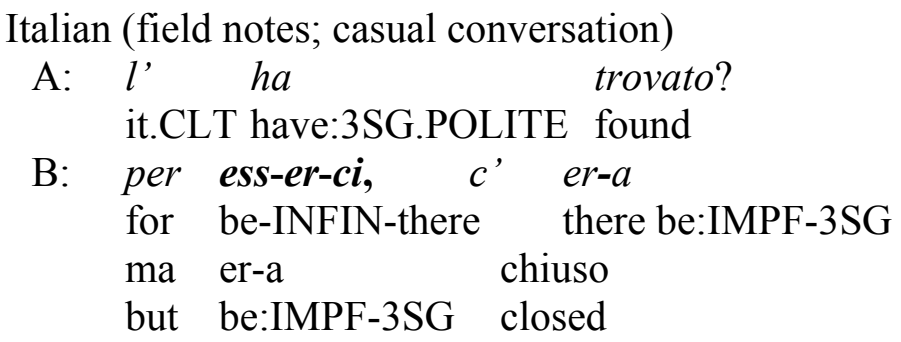

[A is waiting at the side of a street. B passes and asks A where he can find a tobacco shop in the neighbourhood. A shows it to B. After a short time B comes back to the spot where A is still waiting.]

'A: Did you find it?

B: As to its being there, there it was, but it was closed'

In this example, the infinitive in the topic position in B's answer refers to the state of affairs of a tobacco shop being where A indicated, whereas the comment asserts that this state of affair does indeed take place (compare, for example, the English translation, where the topic expression fully specifies the state of affairs). However, the description of the state of affairs (included the predicate) must be copied in the comment, since otherwise it could not be construed as an assertion. In the following example from Russian, the state of affairs referred to by the predicate (the speaker having grown stupid) is negated in the comment. ${ }^{6}$

$$
\begin{array}{lllr}
\text { Russian } & & \\
\text { Ja stal čudakom, njan'ka... } & \text { Poglupet'-to ja } \\
\text { I became } & \text { whimsical.INST nanny } & \text { PFV.grow.stupid:INF-PTCL I }
\end{array}
$$

\footnotetext{
${ }^{6}$ The particle to attached to the topic expression in this example is not obligatory and also occurs with nominal topics.
} 
ěšce ne poglupel, Bog milostiv, mozgi na svoëm meste yet NEG grew.stupid god merciful brains on their place:LOC no čyvstva kak-to pritupil-i-s'

but feelings somehow dulled-PL-REFL

'I have become whimsical, nanny. As for growing stupid, I have not yet, by the grace of God, my brain is at its place, but my feelings are dulled' (Anton Čexov, 'Djadja Vanja')

Example (33) shows the use of an auxiliary instead of a lexical copy of the predicate.

(33) English

She had been opening letters. The paper-knife was there on the desk. Carpenter seized it and drove it in. She may not have meant to kill, but kill she did. (James, P.D., A certain justice, London, Penguin, 1997, p.269).

In examples (34)-(35), the comment asserts a modality expressed by a finite modal verb, without lexical copy of the topic predicate in (34) and with lexical copy of the topic predicate in (35).

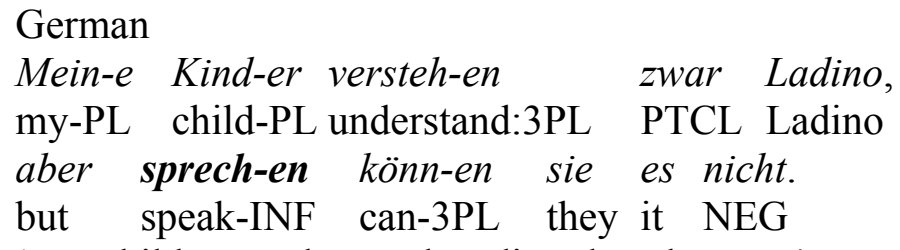

German

Mein-e Kind-er versteh-en zwar Ladino, my-PL child-PL understand:3PL PTCL Ladino aber sprech-en könn-en sie es nicht. but speak-INF can-3PL they it NEG

'My children understand Ladino, but they can't speak it' (Hoş geldin. Die Türkei in kleinen Geschichten, erzählt von Celal Özcan, München, Deutscher Taschenbuch Verlag, 1994, 130-131; example from the German translation of Turkish original)

(35) Spanish

Bueno, pero es una decisión que no la well but is a decision:F.SG that NEG 3SG.F:ACC.CLT toma qualquiera, ¿eh? [...] takes anybody eh

Tomar-la se puede tomar. take:INF-3SG.F:ACC.CLT IMPR can take:INF

'Well, but it is a decision that anybody can take: as for taking it, one can take it' (El habla culta de la ciudad de Buenos Aires. Materiales para su estudio. Tomo 1, Universidad Nacional de Buenos Aires. Facultad de Filosofía y Letras. Buenos Aires, 1987, p. 19). 
In some languages, predicates in the topic position can be expressed by bare infinitives, see (32), (33), (34); this is also possible in Hungarian (36) and in Yiddish (Lockwood 1995: 117).

(36) Hungarian (Jean Perrot, personal communication) figyel-ni figyel-t pay.attention-INF pay.attention-PAST (3SG)

'As to paying attention, he did pay attention.'

In other languages, infinitival topic expressions are accompanied by a preposition meaning 'for', e.g. in Italian (31) and French:

(37) French

Ça sonna. Pour sonn-er, ça sonna. it rang:3SG for ring-INF it rang:3SG

'[I called the jeweller from the nearest pub, Ranelagh 89-10.] It rang.

As for ringing, it rang.' (Léo Malet, Les enquêtes de nestor Burma et les nouveaux mystelres de Paris, Vol. 2. Paris, Robert Laffont, 1986: 195)

Whereas further cross-linguistic research is obviously needed for in-depth understanding of this construction type, it seems plausible to assume, for the time being, that infinitives in topic positions can be used to encode states of affairs as topics.

\section{Semantic grounding of the topic-comment structure}

\subsection{Introductory remarks}

This section links the classification of topic constructions introduced in Sections 3.3 with three distinct semantic ("real-world") relations between the state of affairs described in the comment and the topic referent:

- $s$-topic constructions are grounded in the relation between event and its primary participant;

- $h$-topic constructions are grounded in the relation between event and an entity closely related to one of its participants ("reference point"); 
- $f$-topic constructions are grounded in the relation between event and its spatial/temporal frame.

In spite of their obvious differences, these semantics-based templates are similar in that they combine the description of an event with a reference to a (relatively) stable object, which is essential for topic-comment information structure. Cross-linguistic evidence suggests that these semantic-based structural templates are often employed beyond their primary semantic domains, and it is in such cases that their topic-encoding potential figures most prominently.

Although these semantic templates are presumably universal, their topic-encoding potential obviously varies from language to language: it is often the case that in a given language one template is extensively employed for topic encoding, while others are used in this function only marginally (if at all). In order to avoid possible misunderstanding, it should be stressed that it is not assumed that each of these structures is recruited for topic-encoding function in all languages; the generic statements that may occur in what follows are to be understood as referring only to the universal availability of these options. Another necessary preliminary remark concerns affiliation of particular language-specific topic constructions with one or another structural template. It is not always the case that a single construction identified on the basis of language-specific properties can be affiliated with a single semantic template in an uncontroversial manner. These problems are discussed in Section 5.2.

\subsection{Primary participants}

The first widely attested morphosyntactic phenomenon associated with the concept of topic is "grammatical subject". The complex and cross-linguistically variable relations between "subject", "topic", and "actor" (or, in a more traditional frame of reference, grammatical, logical and semantic subject) have been extensively discussed in the literature. Indeed, the well-established existence of a cross-linguistically relevant class of morphosyntactic structures that are grounded in the event structure and, at the same time, impose a certain "default" information structure serves as the starting point for the more general hypothesis on the phenomenon of sentence topic advocated here. This section 
represents, therefore, a summary of the previous findings (reformulated within the present framework), rather than a new contribution to the domain.

Since the universal validity of the concept of "grammatical subject" - if defined in (morpho)syntactic terms - is a matter of considerable controversy, we shall, for the purposes of the present chapter, define "subject" as a morphosyntactic role - essentially, as a cluster of morphosyntactic features - that encodes the most agentive (in particular, the sole) participant of the event signified by the verb. For European languages, this semantically oriented definition seems to cover essentially the same phenomenological domain as more technically sophisticated and syntactically oriented definitions of subject do, so the change of the definition is not likely to pose any problems. The relevant morphosyntactic features would include case form (where applicable), verb agreement, and linear position, although the relative significance of these features in identification of subject NP obviously differ from language to language. Crucial for the further discussion is the assumption that, as a rule, the choice of relational expression for the role of predicate determines a single element of its valence frame that has a privileged access to the morphosyntactic role of subject, although some other semantic roles can, in some languages, be encoded in the same way with appropriate additional marking within the predicate (most obviously, in passive constructions). This semantic role is referred to here as "primary participant" (PP) role, hence the label "PP-structure" below.

It is widely acknowledged that the subject encoding of NP strongly correlates with topicality of its referent; that is, the overwhelming majority of subjects in discourse happen to be outside the scope of assertion and indeed refer to "what the sentence is about" in some intuitively clear sense (or, to put it in a somewhat weaker form, are most naturally interpreted as "what the sentence is about" without additional clues). This correlation seems so strong, indeed, that the aboutness relation - rather than the primary participant role - can be (and often was) used as the basis of functional definition of subject:

"So far as I can see at present, the best way to characterize the subject function is not very different from the ancient statement that the subject is what we are talking about... it is likely that one of the main ways in which new knowledge is 
communicated - perhaps even the only way - is by identifying some particular as a starting point and adding to the addressee's knowledge about it... We might call this the "adding-knowledge-about" hypothesis regarding the functioning of subjects...” (Chafe 1976: 46-47).

There seem to be three universal factors contributing to this correlation: first, the primary participants are frequently human, and humans presumably universally tend to talk about themselves more frequently than about other things (Hawkinson and Hyman 1975; Comrie 1981: 116-123; Kozinskij and Sokolovskaja 1984; inter alia). Secondly, since the sole participants are also (by definition) primary, the primary participant is frequently just the only possible candidate for being the topic (cf. Lambrecht 1994: 132-133). Finally, the topic referent (if any) and the state of affairs to be described (along with the most appropriate relational expression for this description) are hardly chosen independently (in the speaker's mind): the would-be PP-role (as opposed to a more peripheral role) of the topic referent is likely to be one of the factors that affect the choice of appropriate propositional frame for the comment (the effect most clearly observed in the phenomenon of lexical conversion).

Obviously, these factors determine the correlation of the topicality of a referent with its (primary) participant role, rather than with a specific morphosyntactic encoding; in this sense, the association between topicality and subjecthood (taken as a cluster of morphosyntactic features) is but an epiphenomenal implication of the correlation between topicality and primary participation. The autonomous role of subject-predicate structure in topic-comment structuring of propositions can be visible only in sentences where the primary participant is not the topic referent, i.e. either the sentence has no topic-comment structure to begin with, or the topic referent does not play the primary role in the event being described. The former class of phenomena comprises so-called focuspresupposition ("subject-focus") and thetic (or "broad focus") sentences, e.g.:

(38) Russian

a. Eto sdelal ja!

this make-PST.SG I

'That's me who did it.' 


\section{b. Zvonil mužčina. ring-PST.SG man \\ 'A MAN rang.'}

Languages usually have special morphosyntactic structures and/or intonational patterns signalling that the referential identity (or kind affiliation) of the primary participant lies within the scope of assertion; in such structures, the primary participant can but need not retain the role of subject, i.e., under the definition accepted here, the morphosyntactic features encoding primary participation (for an overview, see, for example, Sasse (this volume) or Kiss (2003); clear examples of both alternatives are provided by the English translations of Russian sentences in (38)). Russian examples in (38) illustrate an "intermediate" strategy most common in Russian (as well as in many other languages), namely, putting the primary NP in an unusual (in this case, clause-final) linear position. The NP thereby loses one morphosyntactic feature of subject, which plays a relatively marginal role in identification of primary participant in Russian ${ }^{7}$ and retains the others (the nominative case form and the control of verb agreement). Obviously, inasmuch as non-topical primary participants regularly lose some coding properties of primary participation, the language-specific correlation between these morphosyntactic features and topicality is strengthened beyond the level determined by the universal correlation between topicality and primary participation; accordingly, the role of these morphosyntactic features in the encoding of information structure is not confined to their role in the encoding of the participant role most commonly associated with topicality. According to Kiss's recent study, non-topical primary participants consistently lose at least some coding properties of subjects in all European languages (Kiss 2003: 693-700).

On the other hand, a language can have a more or less broad range of constructions that involve encoding of a non-primary participant as the subject, and topicality often (or even universally) figures as one of the factors motivating the choice of such constructions in spite of their relative morphosyntactic complexity (see Comrie

\footnotetext{
7 The pre-verbal position emerges as a subject-marking feature only if both the subject and the direct object are referred to by nouns that have identical forms for nominative and accusative case.
} 
1981: 116-123, Keenan 1985: 243-247; Foley and Van Valin 1985: 299-334). Sentences with a non-primary referent "promoted" to the subject role and the primary participant (if specified at all) "demoted" to the clause periphery combine both phenomena. Notably, the choice of subject in such a sentence is more likely to be interpreted as a topicencoding device than in an unmarked sentence with the primary participant in the subject role (see, for example, Davison (1984) about subject as one of the topic-defining positions and Gundel (1988) about "subject-creating" topic constructions). To give just one example of this well-known phenomenon, the Russian passive construction in (39a) strongly suggests that the queue is the topic of this sentence, whereby the primary participant (the speaker) is demoted to the status of reporting witness rather than the sentence topic and the (natural) protagonist of the story (an interpretation further supported by the further of the narrative, which is about a visit to the central office of KGB in the thirties):

(39) Russian

a. Očered' byl-a mnoju zanjat-a ešče $s$ večera. Queue was-SG.F me.INST reserve.PASS-SG.F already from evening 'The queue, I have been keeping my place since the evening.' (Lidia Čukovskaja, "Spusk pod vodu.")
b. Ja zanjal-a očered' ešč $s$ večera.
I reserved-SG.F queue already from evening
'I have been keeping my place in the queue since the evening.'

The use of an unmarked (active) construction (39b) in the same context would be distinctly less marked in terms of topic encoding; although it is likely to be interpreted as information about the speaker, it does not preclude that the queue is $\alpha$-topic. The reason for this difference in interpretation seems obvious enough: there can be several factors that might favour putting the reference to the speaker into the subject position: the semantic role of actor, the first person, and, among others, topicality; accordingly, faced with an active sentence, the listener can assume that the first two factors (and not the topicality) motivate the choice of subject. In contrast to this, the topic status seems to be the only possible motivating factor for encoding the queue as the subject; accordingly, the listener is led to infer that topicality must have overridden all other factors, and thus singling out the queue as the topic was indeed the speaker's intention. According to the 
hypothesis advocated here, these observations suggest that the PP-structure can function as a topic-encoding device beyond its own semantic domain, that is, a linguistic structure grounded in a salient aspect of event structure (primary participant vs. action/state) can lend itself for encoding of information structure (topic vs. comment). Just as the very existence of such constructions in the grammar of a language indicates that the function of the subject role does not amount to primary participation, so the actual use of PPstructure beyond its semantic (role-oriented) domain articulates the information structure more clearly than the unmarked choice of subject.

It should be stressed that this hypothesis is not intended as a hypothesis of diachronic development of specific subject-predicate constructions; that is, it does not imply that the "original" meaning of primary participation associated with the subject gets extended to the information-structuring function; in other words, the association of (language-specific) "subjects" with topicality is not taken to arise as a result of grammaticalization of, say, a passive construction. In fact, it is quite possible that a language-specific subject-predicate construction may result from conventionalization and grammaticalization of a former $h$-topic construction (Givón 1976; Shibatani 1991; inter alia), whereby the topic-encoding potential of this construction is diachronically reduced (rather than extended). Our idea is rather that this aspect of event structure (primary participant vs. state/action) - with its obvious cross-linguistic and presumably languageexternal (perception- and/or cognition-based) relevance - is one of the sources of the linguistic relevance of topic-comment structure, whereby the primary participant is aligned with the topic, and the action/state, with the comment. In this sense, the topiccomment information structure is grounded in the PP-structure, and this link does not depend on the language-specific degree of discourse flexibility of this structure. However, the use of the PP-structure beyond its core semantic domain (e.g. for secondary participants) certainly reinforces this link, which, diachronically, can work as a kind of positive feedback for language speakers and language learners and thus increase the topic-encoding potential of the corresponding structural template. 


\subsection{Reference points}

The class of $h$-topic constructions subsumes language-specific constructions that can be employed for introducing hanging topics (see Sections 3.2 and 3.3 for an overview of this class of constructions in general and in European languages in particular). The primary semantic motivation of the $h$-topic sentence structure seems to be, in effect, negative: its availability ensures the possibility to introduce a reference to the topic without encoding its semantic relation to the comment, or, at another level, without integrating this reference into the propositional structure of the sentence. It seems, however, that there is an important class of "real-world" relations between entities and events that plays a special role in the "positive" semantic grounding of this class of constructions, namely, stable (pre-established) relations between the topic referent and a participant of the situation described in the comment, in particular, between the topic referent and the primary participant of this situation - roughly speaking, the same class of relations that can be encoded as (grammatical) possession. The special role of this class of entity-event relations with respect to $h$-topic constructions is determined by a combination of two properties: on the one hand, the entity does not play any role in the event and thus should not and cannot (in any direct way) be integrated into the propositional structure; on the other, the description of the event is likely to give relevant information about the entity. This class of relations between topic and comment is exemplified in (40)-(42); in (40) and (41a), the possessive-like relation is directly encoded by possessive cross-reference pronouns within the comment; in (41b)-(42), it must be inferred for the proper identification of the referent of subject NP (the package in (41b) and die jüngsten in (42)).

(40) Russian (from Internet chats)

a. Čto že do publiki to eje otnošenije $k$ avtoru what PRT to public:GEN then 3SG.POSS attitude to author:DAT možno opredelit'kak nečto srednee meždu may(IMPRS) define as something middle between 'Blagodarju vas!' $i$ 'Pošel von' thank:1SG you:ACC and sod.off

"As for the public, its attitude towards the author can be described as anything between "I thank you!" and "Sod off!", 
b. Čto že do fonda finpomošji regionam, to what PRT to fund-GEN finanical.help.GEN provinces.DAT then ego objem uveličivaetsja po sravneniju $s 2003$ 3M.POSS volume increases as comparioson.DAT with 2003 godom na $1.5 \%$ year.OBL by $1.5 \%$

'As for the fund for financing the provinces, its size increases by $1.5 \%$ compared to $2003 \ldots$ '.

(41) English

a. As for the homeless, where did their food come from?

b. As for version 1.1, the package includes three utilities.

(42) German $^{8}$

Schürr schrieb: Frankreich wolle er nicht, aber S. wrote(3SG) France want:SUBJ:3SG he NEG but Italien, die jüngsten seien ihm sehr vertraut. Italy DEF youngest be:SUBJ:3PL he:DAT very familiar 'Shürr wrote: France he didn't want, but (as for) Italy, the youngest (authors) were very familiar to him.'

According to Langacker (1993: 24-26), both grammatical possession and the topiccomment relation can be viewed as a manifestation of the same reference-point relationship, or, as Langacker puts it, of "the ability to invoke the conception of one entity for purposes of establishing mental contact with another, i.e., to single it out for individual conscious awareness" (Langacker 1993: 5); it seems reasonable, therefore, to adopt his terminology in the formulation and discussion of our hypothesis and to refer to the structural template under discussion as reference-point (RP) structure. In fact, the concept of reference point is directly related to the $\rho$-topic function, i.e. to anchoring the message in the shared knowledge (see Section 2). For our hypothesis, however, it is

${ }^{8}$ Drawn from Klemperer, Victor (1995). Ich will Zeugnis ablegen bis zum letzen. Tagebücher 1933-1941. Berlin: Aufbau, p. 34. It might be worth noting that, unlike what happened in the case of Italien, integration of the topic object constituent Frankreich in the second sentence of the excerpt is signalled by second-positioning of the verb and by postverbal positioning of the subject $e r$. 
essential to stress that the "reference-point" relation between the topic and a participant of the situation being described (in contrast to the topic-comment relation) is based on a pre-established relation perceived/recognized by the speaker (and, presumably, the listener) as a "real-world" one, and it is this relation that, according to our hypothesis, grounds the RP-structure in the perception and/or cognitive construal of reality.

The cross-linguistic evidence for the special role of the possession-like class of relations between the topic and a component of the comment in the RP-structure is twofold. Direct typological evidence comes from languages where RP-sentences with an explicitly grammatically encoded possession-like relation between the topic and an argument of the main proposition are more integrated into the grammar (i.e. conventionalised to a greater degree) than RP-sentences with genuinely "hanging" topics and/or RP-sentences featuring other relations between the topic and the comment. In Yukaghir, for example, sentences with a possession-like relation between the topic and an element of the comment constitute the only fully conventionalised class of RP-sentences with morphologically unmarked topic expression; the topic must be cross-referenced within the comment by a bound possessive pronoun (-gi- or -de-depending on the case form of the possessed), e.g.:

(43) Tundra Yukaghir (field notes)

a. tay paj es'ie-gi tan pulut-ket joulos'-l'el-um that woman father-3SG that old.man-ABL ask-INFR-3SG 'That woman, her father asked that old man.'

b. tay pulun-die n'u:-gi Pottuo l'e-l that old.man-DIM name-his P. BE-SF 'That old man, his name was Pottuo.'

c. tay paj ör-de-get met önme bojs'e šohie-j that woman cry-her-ABL my mind completely get.lost-3SG 'That woman, her cry made me mad.'

In Tz'utujil, the RP-structure (with unmarked pre-verbal topic expression) is conventionalised for topics that are either participants of the event being described (44ab) or are linked to a participant of this event by a possession-like relation (44c) (Aissen 1999). 
(44) Tz'utujil (Aissen 1999: 170, 180)

a. Ja r-me'al $x$-ok-i Malincha

The A3SG-daughter CMPL-enter-IV Malincha

'His daughter played the role of Malincha.'

b. Ja w-xaayiil x-in-k'am el San Jwaan

The A1SG-wife CMPL-A1SG-take DIR San Juan

'I took my wife to San Juan.' (170)

c. Ja keej qas nim ruu-jeey

The horse very big A3SG-tail

'The horse has a long tail.'

Moreover, RP-sentences featuring the possession-like relation between the topic and an element of the comment ("double-subject" sentences) appear to have a special grammatical status in topic-prominent languages as well (Kumashiro \& Langacker 2003) and have been claimed to play a major role in grammaticalization of this structure in general and, consequently, in the rise of "topic-prominence" as a typological state of language (Li \&Thompson 1976: 480, 484). Some typical examples of such sentences from a topic-prominent language are given in (45).

(45) Korean (Li \& Thompson 1976: 468, 480)

a. Pihengi-nin 747-ka khi-ta

Airplane-TOP 747-SBJ big-stat

'Airplanes, the 747 is big.'

b. John-in meli-ka aphi-ta

John-TOP head-SBJ sick-STAT

'John has a headache.'

In this sense, the distribution of RP-sentences with regard to the RP-relation parallels the distribution of PP-sentences with regard to the PP-role: the availability of RP-structure for "possessors", just as the availability of PP-structure for primary participants ("semantic subjects") constitutes the typologically unmarked case. That is, if an RPconstruction is conventionalised at all, it is conventionalised for possessors, but not vice versa.

The second piece of evidence comes from the fact that the "possessor" of an entity participating in the situation is quite frequently the $\alpha$-topic of a description of this situation (i.e. what this description is about), especially for such semantic sub-classes of 
grammatical possession as whole-part (in particular, body-part; see (43c), (45b)), kinship (43a), and arguments of relational nouns): for example, describing a state of affairs involving someone's body part is (more often than not) intended to increase the addressee's knowledge about the person in question (rather than about their body part). More generally, the same factors that make a referent an appropriate reference point for an entity involved in the situation being described increase the likelihood of this referent being the $\alpha$-topic of this description; to put it the other way round, it is often the case that adding information about a referent involves predicating something of a closely related entity. From the purely structural point of view, the RP-sentences appear to instantiate the iconic strategy for encoding this information structure. Compare, for instance, the example from Mandarin Chinese in (46) and its possible English counterparts in (47)

(46) Mandarin (Li \& Thompson 1976: 468)

nèike shù yèzi dà that tree leaves big 'That tree, leaves are big'

(47) a. That tree has big leaves.

b. The leaves of that tree are big.

c. (As for) that tree, its leaves are big.

Assuming that the information to be added about 'that tree' is the information about the size of its leaves, not about its having leaves, syntactically and pragmatically 'unmarked' English options are obviously non-iconic as far as information structuring is concerned: a have-based structure in (47a) indicates the topic by means of the PP-strategy, yet this is only possible because the statement is structured as a predication of possession, whereas the actual predication of property is packed into a noun phrase; conversely, a genitivebased structure (47b) does succeed in presenting the statement as a predication of property, but obviously fails to make the topic-comment structure syntactically transparent. The RP-structure in (47c) - which is, in effect, structurally equivalent to the Mandarin original - resolves this conflict, but at the cost of resorting to a less conventionalised and/or morphosyntactically and pragmatically more "marked" structure. It seems, indeed, that a relatively peripheral status of RP-sentences in European 
languages correlates with the existence of another conventionalised strategy for indicating topicality of reference points. In English - and, for that matter, in "Standard Average European" - this alternative strategy is represented by HAVE-based constructions (as exemplified in (47a)), which allow the speakers to employ the PP-scheme to encode this type of information structure (Langacker 1995; Aissen 1999); ${ }^{9}$ other European languages resort to a strategy based on spatial framing to accomplish the same information-structuring goal (see Section 4.4). This correlation can be construed as indirect evidence in favour of the hypothesis of the intrinsic link between the RPstructure and a presupposed relation between the $\alpha$-topic and an argument of the main predication.

On the other hand, the role of RP-structure as a strategy of encoding the aboutness relation becomes particularly obvious if it is employed beyond its primary semantic domain, i.e. for topics that are integrated into the main proposition (participate in the situation being described), especially for primary participants (as illustrated by sentences (b) in examples (48)-(51) for some European languages).

(48) French (Hagelge 1985/1989: 219)
a. Les chiens mordent quand on les provoque DEF dogs bite.3PL when IMPERS them provokes
b. Les chiens, ça mord quand on les provoque DEF dogs this bites when IMPERS them provokes 'Dogs bite when provoked'

(49) German (Jacobs 2001: 658)
a. Peter kommt morgen P. come.3SG tomorrow
b. Peter, der kommt morgen. P. he.DEM come.3SG tomorrow.

${ }^{9}$ Another possible way to subsume this type of information structure under the PPscheme is subject-incorporation. This strategy is described for Chukchee (Nedjalkov 1977), e.g.:

Ytlyg-yn k'aa-v'e-g'e

Father-SG:ABS deer-died-3SG

'Father, (his) deer died.' 
'Peter is coming tomorrow.'

(50) English (Givon 1976: 153)

a. The wizard lived in Africa.

b. Now the wizard, he lived in Africa.

(51) Russian

a. Pervyje mysli samyje pravil'nye first thoughts most right 'The first thoughts are most true.'

b. Pervyje mysli oni samyje pravil'nye first thoughts they most right

'The first thoughts, they are most true.' (from an Internet chat)

Here, again, the emerging picture is homomorphous to that discussed in Section 4.2 for the PP-structure: whereas a $h$-topic from the primary semantic domain need not encode the $\alpha$-topic, the use of this structure beyond its primary semantic domain strongly suggests the aboutness relation between the topic and the comment. By the same token, the RP-encoding of the primary participant is a stronger indication of its topic role than the PP-encoding (cf. examples (a) and (b) above).

\subsection{Spatial frames}

The topic-encoding structures discussed so far do not cover a class of constructions which plays a major role in a number of European languages, namely, constructions in which the semantic relation between the topic and the comment is encoded on the topic expression, by means of the same relational marker (a case marker and/or an adposition) that would be used for non-topical constituents in the same role (f-constructions in terms of 3.3). This construction class is illustrated by the following examples:

(52) Italian (Bernini 1992a: 44)

Alla casa dell' Impruneta ci andav-ano poco to:DEF house of:DEF Impruneta LOC.CLIT went-3PL few

'To the house of Impruneta, they used to go there rarely.'

(53) French (Cadiot 1992)

Aux enfants je pardonne tout to:DEF children I forgive:1SG everything

'To children I forgive everything.' 
(54) German

Mir sind seit gestern noch eine Menge Fragen

I:DAT are since yesterday still a quantity quiestions

eingefallen

come.to.mind

'A lot of questions has come to my mind since yesterday' (Jakob Arjouni, 'Happy Birthday, Türke! Ein Kayankaya-Roman')

(55) Russian

a. Etu poemu Ivan Nikolaevič sočinil,

This:ACC poem:ACC I.:NOM N.:NOM compose:PRT:3SG

$i v$ očen' korotkij srok

and in very short:ACC time:ACC

'This poem Ivan Nikolaevich has composed, and in a short time...' (Mixail Bulgakov, "Master i Margarita".)

b. $V$ reljacionnoj grammatike osnovnoje vnimanie udeljaetsjane procedure

In relational:OBL grammar:OBL

is:given NEG procedure:DAT

otoždestvlenija sintaksičeskih otnošenij...

identification:GEN syntactic:GEN relations:GEN

'In the relational grammar, the attention is focused not on the procedure of the identification of syntactic relations...' (A.Kibrik)

The morphosyntactic form of topic expression is determined by its role in the proposition, and the structuring of information is achieved by fronting, which can be accompanied by a break in intonation contour and/or a pause; in some languages, fronting of the topic expression requires cross-referencing of the topic within the comment (cf. the locative clitic in (52)).

The hypothesis we would like to present in this section is that this topic-encoding strategy is grounded in the relation between the event and its spatial/temporal location, in the same way as the PP-strategy is grounded in the relation between the event and its primary participant, and the RP-strategy, in the relation between the event and an entity related to one of its participants. This structure will be referred to as spatial-frame, or SFstructure. As in the preceding cases, the hypothesis is based on three types of considerations: (i) the description of a state of affairs can provide relevant information about the place/time where this state of affairs holds, whereby the place/time of an event assumes the $\alpha$-topic status with respect to the description of this event; (ii) fronting of 
spatial/temporal "scene-setters" is less typologically marked than fronting of other components of the proposition (Paršin 1983); (iii) the topic-encoding potential of the SFstructure is stronger (more visible) if it is applied beyond its (hypothesized) primary semantic domain.

The first point can be illustrated by the following example:

(56) Russian

$V$ našej strane ateizm nikogo ne udivljaet

In our:OBL country:ABL atheism:NOMnobody:ACC NEG surprise:PRES:3SG

'In our country atheism does not surprise anybody.' (Micahil Bulgakov, "Master i Margarita”)

Although the initial constituent of (56) specifies the location within which the situation being described takes place, the sentence is to be interpreted as adding to the addressee's knowledge about "our country". This interpretation is supported by the text from which the example is excerpted: the addressee of this remark extensively expresses his gratitude for very interesting and important information about the country.

It goes without saying that not every clause-initial spatial/temporal adverbial can be reasonably interpreted as "what the sentence is about", i.e. the SF-structure used within its primary semantic domain need not encode the $\alpha$-topic (see, however, Maienborn 1996; Jacobs 2001). However, the topic-encoding function of the SF-structure becomes more transparent if the locative relational expression is used metaphorically (as in (55b), (57) and (58)).

(57) English

In English we can do something similar with certain temporal adverbs (W. Chafe).

(58) German (Jacobs 2001: 657)

In meinem Traum war Peter ein Krokodil

In my dream was $P$. a crocodile

'In my dream, Peter was a crocodile.'

As in the previous cases, the SF-structure can be used beyond its primary (spatial/temporal) semantic domain for encoding topicality of participants of the situation 
being described, whereby the relational marker on the topic expression reflects the actual role of the topic in the situation; this is illustrated in (53) and (55a) above. A further piece of evidence in favour of topic-indicating potential of the SF-structure is given by languages that use locative expressions in predications of possession, $\mathrm{cf}$. the following Russian examples:

(59) Russian (native competence)

a. U zabora stoja-l-a

lošad'

At fence-GEN stand-PRET-SG:FEM horse:NOM

'A horse stood near the fence.'

b. U Ivana by-l-a kvartira

At Ivan:GEN be-PRET-SG:FEM apartment:NOM 'Ivan had an apartment.'

This structure can also be employed if some information about an entity is provided by predicating a property of a related entity for which the topic can serve as a reference point, that is, the SF-structure can be used for topic-encoding beyond its primary semantic domain and extended to the semantic domain of RP-structure:

Russian

(60) a. U Ivana bolit golova

At Ivan:GEN sick:PRES:3SG head:NOM

'Ivan has a headache.'

b. U menja ženilsja syn

At me:GEN marry:PAST:3SG son:NOM

'My son has married.'

c. Moj syn ženilsja

My son:NOM marry:PAST:3SG

'My son has married.'

The sentences of this type are constructed in such a way as to encode the reference point for the subject as the topic (cf. the distinction between (60b) and (60c)), and it is the SFstructure that is employed for this purpose. As expected, the SF-topic of such sentences consistently coincides with the $\alpha$-topic. 


\subsection{Three semantic templates vs. three aspects of topicality}

In Sections 4.2-4.4, we focused on the inherent association between three types of "real world" relations between entities and states of affairs (and the corresponding structural templates) and the intuitive concept of aboutness ( $\alpha$-topic), which, as we assume together with the grammatical tradition, is the closest approximation to the hypothesized mental status of topic. In this section, we discuss their relationship to two other aspects of topicality mentioned in Section 2, $\sigma$-topic and $\rho$-topic.

The concept of $\rho$-topic goes back to the Prague circle's "theme vs. rheme" distinction; it was introduced to account for word order variations in Slavic languages (Mathesius 1929), that is, in our framework, for the topic-encoding usage of the SFtemplate, and reflects the general observation that entities referred to by clause-initial constituents tend to be "given", whereas new information is added later. ${ }^{10}$ In the modern accounts of topicality, this idea is elaborated and refined in terms of identifiability of topic referents to the listener and the degree of their activation in the listener's mind (Chafe 1976, 1987; Gundel et al. 1993; Lambrecht 1994; inter alia). As mentioned in 4.3, the relevance of this aspect of topicality to the RP-template follows directly from its primary reference-point function: an entity can serve as an appropriate reference point for something else only insofar as it is better anchored in the shared knowledge. The association of the $\rho$-topic function with the PP-template is determined by one of the universal correlations that link this template with topicality in the first place (see Section 4.2): primary participants are frequently humans, and thus central topics of discourse; accordingly, they are most likely to be previously mentioned (and thus activated). Strikingly, the SF-template is in fact less straightforwardly associated with the $\rho$-topic function; we will return to this issue in the end of this section.

The concept of $\sigma$-topic was introduced to describe the functions of $h$-topic constructions, i.e. of the RP-topics in the conceptual framework introduced above. Li and Thompson (1976: 463-464), in their extensive discussion of topic-prominent languages,

${ }^{10}$ Major contributions in the research tradition of "Functional Sentence Perspective" are collected in a volume edited by Sornicola \& Svoboda (1991). For a general introduction to the theory and method of "Functional Sentence Perspective" see Eroms (1986). 
accept Chafe's functional characterization of "Chinese-style" topics, which states that it "sets a spatial, temporal, or individual framework within which the main predication holds" (Chafe 1976: 50). Indeed, the RP-topic expression can limit the applicability of the main predication, in a clearly definable semantic sense: if it does, then the sentence does not entail its comment (Jacobs 2001: 656-658), i.e. a sentence consisting of the comment only would be, at least without sufficient contextual clues, interpreted as applicable to a broader class of situations. For instance, consider an example of topiccomment sentence from (Li \& Thompson 1976: 459):

(61) As for education, John prefers Bertrand Russell's ideas.

The sentence does not entail its comment, insofar as the latter (without activation of the topic referent) is assumed to mean that John prefers Bertrand Russell's ideas in all domains of knowledge enriched by Russell's contributions. However, the concept of frame setting, if defined in purely semantic terms, does not apply straightforwardly to all instances of $h$-topic constructions. Sentence (62) (the English translation of German example (15)), according to Jacobs' interpretation, does entail its comment: the municipal theatre plans a performance of "Faust" independently of whether this information is related to Goethe's anniversary; consequently, Jacobs claims that the $\sigma$-topic function cannot be viewed as an intrinsic property of the as-for construction (and nor of the German was X betrifft construction):

(62) As for Goethe's $2 \mathbf{2 5}^{\text {th }}$ birthday, the municipal theater plans an unabridged performance of "Faust".

However, the apparently obvious distinction between sentences like (61) and (62) becomes blurred if the context (in the most general sense of the word) is taken into account. On the one hand, if the comment of sentence (61) occurs as an independent sentence in the context of a conversation about education, the meaning conveyed by this sentence would be exactly the same as the meaning of the original sentence (with the RPtopic attached). On the other hand, (62) does not delimit the domain of applicability of its 
comment only insofar as Goethe's rendition of the story of Doctor Faust is taken to be the (only) one; insofar as the shared cultural knowledge of the interlocutors includes other versions of the story and does not single out Goethe's version as the Faust, the RP-topic certainly delimits the set of potential referents of "Faust", and thus the domain within which the main predication holds. To illustrate this point by another example, it is very likely that a sentence like $[$ As for X] I like "Eugene Onegin" very much will be interpreted differently by different readers of this paper: for some, $X$ is most likely to be Alexander Puškin, for others, Pyotr Čajkovskij; and one cannot even exclude Ralph Fiennes as a possible topic of such a sentence. Depending on what the (explicit or implicit) topic is, the referent of "Eugene Onegin" would be the poem, the opera, or the movie with this title. The point is that a sentence like As for Pulskin, I like "Eugene Onegin" very much would seem, out of the context, to entail its comment (at least to our Russian readers) just as (62) seems to entail its comment, yet a sentence like I like "Eugene Onegin" very much can also be truthfully said by someone who has no idea of the referent of the first sentence and just likes the movie. This digression into a discussion of cultural differences, which may appear to have little to do with linguistics, is intended to demonstrate the $\sigma$-topic aspect of topicality cannot be reduced to a purely semantic notion. In the case of RP-topics, it is inherently associated with their primary referencepoint (i.e. $\rho$-topic) function, i.e. with anchoring the proposition in the shared knowledge: the activation of topic referent narrows down not the out-of-the-context propositional meaning of the comment, but the message that would be conveyed by the comment alone in the given context (where the context is taken to include both the current discourse and speech situation and the relevant cultural context).

The concept of $\sigma$-topic has been defined in such a way that it cannot be straightforwardly applied to the PP-template, since a PP-topic is not semantically separated from its main proposition. If the contents of the comment is construed as the main proposition with unspecified primary participant, then the sentence obviously entails its comment and thus does not delimit the domain within which the proposition holds (for example, a sentence like The man kissed the woman entails something like The woman was kissed or Someone kissed the woman (cf. Jacobs 2001: 646, 656)) On the other hand, the comment of a PP-sentence is, as a rule, encoded in such a way as to 
indicate that the referential identity of the primary participant is specified (The man kissed the woman is not semantically identical to something like As for the man, someone kissed the woman.) In this sense, specification of primary participant certainly does impose additional truth conditions and thus delimits the individual domain within which the comment holds. Accordingly, the concept of $\sigma$-topic applies to PP-topics insofar as the comment of a PP-sentence differs from a sentence with unidentified subject reference (which seems to be the case in all European languages).

Finally, the inherent affinity between the SF-template and the $\sigma$-topic function seems to be beyond reasonable doubt: delimitation of the domain within which the state of affairs takes place can well be viewed with the primary function of sentence-initial "scene-setters", whether or not the template is used beyond this semantic domain in a given language. Since the existence of a specific spatial/temporal locus of the event is implied for most sentences (cf. Kratzer 1998, 1995), but its explicit specification is not, as a rule, syntactically obligatory, the primary scene-setting function determines the range of contexts where SF-sentences are likely to occur: these are the contexts where identification of the spatial/temporal domain of the state of affairs is essential for interpretation, but the spatial/temporal domain of the previously mentioned states of affairs is either broader or simply different. For example, the Russian sentence in (56) without the SF-topic expression could be interpreted as applying either more broadly than intended (e.g. as a statement concerning the world as a whole), or, in the context of a conversation about some other country, as a statement about that country. This results in a special type of anchoring of the sentence in the context (i.e. of the $\rho$-topic function) associated with the SF-template: it is based not on a prior activation of the SF-topic itself, but rather on a prior (explicit or implicit) activation of other spatial/temporal locations. As a result, the SF-template is inherently associated with contrastivity; for example, fronting the reference to 'our country' in (56) implies the existence of other countries where atheism can be rare and therefore surprising. This aspect of meaning can be retained in sentences where the SF-template is used beyond its primary domain (cf. Chafe 1976; Paršin 1983; Büring 1999; inter alia).

To sum up this section, each semantically grounded structure discussed in this section is inherently linked with one aspect of topicality: primary participants, with the $\alpha$ - 
topic function, spatial frames, with the $\sigma$-topic function, and reference points, with the $\rho$ topic function. In each case, however, one function triggers the others, so that each template comes to be associated with all three aspects of topicality. In our view, this corroborates our hypothesis that the hypothesized mental status of topic joins together three linguistic templates directly grounded in our construal of reality.

\section{Language-internal and cross-linguistic variation in topic encoding}

\subsection{Competition between topic-encoding templates}

The hypothesis outlined above entails that there are three universally available semantically grounded templates for articulation of the topic-comment structure of the message; this provides the basis for language-internal variation in topic encoding. Assuming the intended meaning consists of a topic referent $t$ and a comment most adequately conveyed by a proposition $P$, the speaker has a choice between four universally available options, which can be schematically represented as follows:

PP-template: $\mathbf{S}\left(P^{\prime}(t)\right)$

SF-template: $\mathbf{S}(R(t)+P)$

RP-template: $t+\mathbf{S}(P)$

No topic encoding: $\mathbf{S}(P)$

$\mathbf{S}(\ldots)$ signifies encoding of the information in the form of an independent sentence, $R(t)$ indicates that the topic expression has the form required by its role $(R)$ in the proposition $P$, and $P$ ' indicates that the proposition may need to be modified in order to encode $t$ as the primary participant. This schematic paradigm is exemplified in (64).

(64) Russian

a. Čto do ošibk-i, to Efremov sam pišet o nej v what to error-GEN then E. RFL writes about 3SG.OBL in predislovi-i $k$ svoemu sobraniju sočinenij introduction-OBL to RFL.POSS.DAT collection.DAT works:GEN 'As for the error, Efremov writes about it himself in the introduction to his collected works.'

b. Ob etoj ošibk-e Efremov sam pišet $v$ 


\author{
about this error-OBL E. INTSF writes in \\ predislovi-i $i$ svoemu sobranij-u sočinenij \\ introduction-OBL to RFL.POSS.DAT collection-DAT works:GEN \\ 'Efremov writes about this error himself in the introduction to his collected works.' \\ c. Eta ošibk-a opisana samim Efremovym $v$ \\ This error-NOM described INTSF.INST E.INTST in \\ predislovi-i $k$ ego sobranij-u sočinenij \\ introduction-OBL to his collection-DAT works:GEN \\ 'This error is described by Efremov himself in the introduction to his collected \\ works.' \\ d. Efremov sam pišet o nej v \\ E. INTSF writes about 3SG.OBL in \\ predislovi-i $\quad k$ svoemu sobranij-u sočinenij \\ introduction-OBL to RFL.POSS.DAT collection-DAT works:GEN \\ 'Efremov writes about it himself in the introduction to his collected works.'
}

Sentence (64a) is an authentic example found on an Internet forum and instantiates the RP-template. The topic referent (an error in one of the editions of Efremov's book) is one of two topics of the discussion from which the example is extracted; it can be assumed to be activated in the minds of all interlocutors. Having said something about the other discourse topic, the author of this comment switches back to the error in question. In contrast to this, if the error had been established as the current topic of discussion and named as such in the preceding sentence, the speaker could choose not to encode it as a structural topic, but just to refer to it by means of a pronoun, the resulting sentence being identical to the comment of the original example (cf. examples (64a) and (64d)). The $s$ construction in (64c) (i.e. the PP-template) would be appropriate if the topic is continuous but has not yet been referred to as ošibka (for example, following a description of what is considered an error). The SF-template in (64b) would also sound natural in such a context, but it is more likely than the s-construction in the context of contrastive topic (for example, if the speaker wishes to imply that there are other errors described elsewhere or unnoticed by the author). Essentially the same range of discourse-sensitive factors, albeit in a somewhat different fashion, affect the output of similar competitions between coding options in other languages. Let us return to our first example, repeated here as (65).

(65) English 
a. [inspector] "You are not to open any letters unless you recognize the handwriting," he said.

b. "Everything else we'll look at first.

c. As to the phone calls..."

d. [woman] "Your sergeant said you'd have an arrangement to get my phone monitored” (Ruth Rendell, No more dying then. An Inspector Wesford Mystery.)

The PP-topic in (65a) is established as a continuous topic by the speech situation. The SF-template in (65b) explicitly contrasts two classes of letters which are to be dealt with in different ways; the form of the topic expression links it to the preceding sentence (insofar as everything else is to be understood as "other letters"). Finally, the (beginning of) RP-template in (65c) signals a switch to a different topic, which is obviously less activated by the preceding conversation than the SF-topic in (65b) but is also explicitly contrasted to the previous topic ("letters").

The tendencies exemplified by (64)-(65) appear to be universal and directly follow from the universal properties of topic-encoding templates outlined in Section 4. To begin with, the range of of discourse contexts in which the PP-template can be felicitously used would include the contexts of continuous (i.e. highly activated and inferrable) topics, whereas the RP-template is more likely to be used for less accessible topic referents. This tendency is a direct implication of the inherent properties of these templates outlined in Sections 4.2-4.3. In most cases, the primary participant is a necessary component of the state of affairs, independently of whether or not it is overtly expressed: if not, it is normally taken to be "dropped" and its antecedent is to be looked for in the preceding context. In contrast to this, if no RP-topic is present, it is not "dropped", it is just absent. For example, the sentence John prefers Bertrand Russell's ideas (cf. (61)), even if produced when the listener is assumed to understand it as true only for education, would not be identified as an instance of $h$-topic construction with a "dropped" topic; similarly, (64d) would not be identified as an instance of the RPtemplate (identical to (64a) with topic “dropped"). Otherwise, we would have to describe almost all sentences taken from a coherent piece of discourse in this fashion, i.e., as "containing" a number of "dropped" reference points which are derivable from the preceding context (for example, all English sentences with anaphoric pronouns as instances of left-dislocation with "dropped" left-dislocated constituent). Although this 
approach may be in a sense helpful for analysis of discourse coherence' it does not seem reasonable for syntactic typology. Insofar as sentences are identified as instances of the RP-template if the topic expression is overtly present in a sentence, its is bound to be limited to discourse contexts in which the topic referent is not highly activated by the time of utterance. The PP- and RP-templates are thus bound to contrast in terms of their availability for highly activated referents.

The role of the SF-template in the overall system of topic encoding is subject to a more considerable cross-linguistic variation. On the one hand, it presupposes a higher level of integration of the topic expression into the propositional structure, insofar as their relation $R$ has to be encoded morphosyntactically. As a result, it need not be associated with the points of topic discontinuity (in contrast to the RP-template) and can be employed to "compensate" for inherent semantic constraints on the PP-template. For example, the choice between the SF-template and the PP-template in (64b) and (64c) respectively in the context of continuous topic can be motivated by purely semantic considerations: assuming that the comment of the original example is the optimal expression of the speaker's intended meaning (i.e. proposition $P$ ), the PP-template requires a slight modification of this meaning: in order to encode the error as the subject, the speaker must integrate it into the propositional structure by transitivizing the main verb, which happens to involve a change in aspect and tense as well (instead of the present imperfective of other alternatives, this one has past perfective main predicate). Although the resulting difference between the encoding options amounts to delicate semantic nuances, this semantic distinction can be significant from the point of view of the speaker's actual intentions and thus rule out the use of the PP-template. Obviously, this language-specific factor reflects an inherent property of the PP-template: depending on the relation $R$ between $t$ and $P$, the modification of $P$ invovled by the PP-encoding (referred to as $P^{\prime}(t)$ in (63)) can turn out substantial enough to rule out this option and limit the competition to other alternatives. Although the scope of the resulting constraints on the use of PP-template vary from language to language (Keenan 1985: 243-247; Foley and Van Valin 1980; 1985: 299-334), the very presence of such constraints is determined by the inherent properties of the PP-structure and is therefore universal. On the other hand, as described in Section 4.5, the SF-template is intrinsically associated with 
contrastive topics, i.e., with contexts where the topic referent has to be explicitly singled out from a contextually determined set of entities that would be associated with other propositions (see (Paršin 1983) for a detailed discussion of this issue). Insofar as the PPstructure is (relatively) broadly available for encoding of continuous topics, the SFstructure would tend to be constrained to contrastive topics (as in English, cf. (65b)).

Another factor that can affect the choice of one topic-encoding template over the other is the presence of another topic in the intended meaning. For example, the SFsentence in (64b) and the PP-sentence in (64c) differ in terms of the locus of the agent (Efremov) in the information structure: the SF-template construction allows for encoding of the primary participant as "hyper-topic" (Kuno 1987: 17), as in the original example (64a): Efremov constitutes a more global topic, and within this general domain, one of his errors is singled out as the local sentence topic (Lambrecht (1994: 147-150) uses the terms "primary" and "secondary" topic(s) instead). ${ }^{11}$ The use of PP-template for the object participant precludes encoding of the primary participant as "hyper-topic": in (64c), this referent must be included into the scope of assertion (in contrast to the original example). This difference can play a more or less significant role in the choice of encoding options depending on the speaker's intentions. As in the previous cases, this factor can be thought of as a language-specific instantiation of cross-linguistic constraints. Generally, two structural templates can be combined with a single sentence to point to two different topic referents, so that the template encoding the local sentence topic "embeds" the template encoding the hyper-topic as its comment. Language-specific

11 According to Vallduví (1993) and Kiss (2003: 691), a sentence can have two functionally equivalent topics; although it seems difficult to evaluate this claim on the basis of constructed examples, we hypothesize that the local vs. global opposition can be more or less sharp depending on the context, and the situation of equivalent topics is possible as a "limiting" case, where this opposition is neutralized. Indeed, there is nothing in the hypothesis of existence for sentence topic that would entail that only one entity per sentence can assume this mental status (in contrast to the "mental addressation" model, which explicitly excludes the possiblity of multiple topics (Reinhart 1982)). 
constraints on such combinations appear to conform to the following hierarchy, which can be viewed as a direct implication of the inherent properties of the templates:

$$
\text { Reference Point }>>\text { Spatial Frame }>>\text { Primary Participant }
$$

The use RP-template for encoding of the local topic tends to licence a hyper-topic encoding in all languages, as illustrated by sentences (64a) (for Russian), (61) (for English) and (62) (for German). In contrast to this, the PP-template does not allow for embedding of another topic-encoding template as its comment. The ability of the SFtemplate to embed the PP-template is subject to cross-linguistic variation: for example, this combination is possible in Russian (see (64b)) and in English (65b), but not in German. On the other hand, the SF-template can be easily "embedded" into the RPtemplate for hyper-topic encoding in Russian, but not in English. As a result, Russian allows for a combination of three hierarchically arranged topics, as demonstrated by (67). Here the discourse topic ("hyper-topic") is the enrollment advantages (encoded by means of the innermost PP-topic); within this domain, the speaker talks about the legal basis of these advantages (the law of Russian Federation, encoded by means of the next-level SFtopic); finally, the local sentence topic within this domain is the national-level competitions for gifted high-school students, encoded as a RP-topic.

(67) Russian

Čto kasaets'a obščerossijsk-oj olimpiad-y to po zakon-u What concerns all.Russia-ADJ.GEN Olympics-GEN then PREP law-DAT $\boldsymbol{R}$ l'got-y predostavl'ajuts'a tol'ko pobedit'el'-am RF advantage-PL give:PASS.PL only winner-PL.INST 'As for the national competition, the law of Russian Federation gives enrollment advantages only to the winners.' (from an interview given by the rector of Moscow State University)

To sum up, if the intended meaning invokes a hyper-topic, the encoding of local topic can be chosen in such a way as to allow for a hyper-topic encoding. Most commonly, this factor will disfavour the use of the PP-template if the local topic does not coincide with the primary participant and the hyper-topic does. 
Finally, the choice of a topic-encoding template can be affected by markedness considerations. The first relevant aspect of markedness is structural markedness, or, in other terms, the economy principle (Haiman 1983); in particular, the considerations of economy would favour sentences where the topic is referred to once over those that contain a (nominal or pronominal) cross-referencing expression. Language-specific rules that require cross-referencing the topic generally follow the hierarchy in (66). To begin with, the comment of RP-template is, by definition, encoded as an independent sentence (which would occur in the context of highly activated topic); accordingly, it is most likely to require cross-referencing. No overt cross-referencing expression is needed only if the language allows zero discourse anaphora, which seems to be the case in all topic prominent languages. In other words, the RP-template can be consistently preferred over other templates only if it is never "penalized" by the structural markedness considerations. In the language of Europe, this condition is not satisfied. In contrast to this, the PP-topic is least likely to require cross-referencing by an independent pronoun. The SF-template occupies the intermediate position. In particular, it does require crossreferencing in some European languages (e.g., in Italian, see (52) and (68)) but not in others (e.g. in Russian and in English, see (64b) and (65b)).

Italian (native competence)

A Giovanni la proposta non lo convince to John the proposal NEG OBJ.3SG.M convinces 'The proposal doesn't convince John.'

If the SF-template does not require cross-referencing, the structural markedness considerations favour this template over the RP-template; otherwise, they favor the PPtemplate over the other two templates.

The second aspect of markedness, which can be referred to as pragmatic markedness, is negatively correlated with the discourse frequency of the construction (cf. Dryer 1995): each instance of a construction "reinforces" it in the minds of interlocutors and thus increases its degree of conventionalization and makes it more readily available in other contexts and speech situations; in other words, an increase in discourse frequency serves as a positive "feedback" for the language speakers in the sense that it is likely to 
lead to a further increase in frequency. The third and final relevant aspect is the semantic markedness, i.e. the ability of a construction to signal unambiguously the topicality of a referent; the semantic markedness of a topic-encoding template decreases if the corresponding morphosyntactic structure can coincide with the no-encoding option, i.e. if the morphosyntactic distinction between a topic-encoding template and the absence of a topic encoding can be neutralized. Whereas both aspects of markedness can be assumed to be relevant universally, languages obviously differ in the degree of pragmatic and semantic markedness of the competing templates. This variation is discussed in further detail in the next section.

\subsection{Neutralization of formal distinctions between topic-encoding templates}

In some languages, the paradigm of competing encoding options can be, in some contexts, reduced by neutralization of the distinction between the different structural templates. One type of neutralization can be referred to as "merged" topic encoding: in some languages, the morphosyntactic constructions corresponding to distinct coding options listed in (63) can turn out to be identical for some relations $R$. The most trivial case of merged encoding is the identity of PP-encoding and SF-encoding with the noencoding option for primary participants of $P$ and spatial/temporal settings respectively. This situation was discussed in Section 4.2 with reference to example (39b): the use of an active construction does not ensure unambiguous encoding of the topicality of the primary participant. Moreover, for topic referents coinciding with primary participants the PP-template and the SF-template are merged in subject-initial languages: whether the speaker chooses the PP-template or the SF-template, the result will be the same subjectinitial structure. This, in effect, reduces the competition to two distinct candidates (roughly speaking, the RP-template vs. no encoding), which means that the RP-template emerges as the only option for unambiguous encoding of topic-comment structure for primary participants and spatial/temporal frames. The SF-template and the RP-template can merge into the same sentence structure if they impose similar requirements on crossreferencing the topic within the comment, i.e. if their comments can have the same morphosyntactic form. Under this condition, the templates are merged in sentences where 
the role of topic in the propositional structure of the comment does not require overt marking. The following example from Italian illustrates this point:

Italian

Il coraggio, uno non se lo può dare the courage one NEG REFL.DAT OBJ.3SG.M can:3SG give:INF 'One cannot give himself courage.' (Manzoni, I promessi sposi)

This sentence can instantiate either the SF-template (the topic expression has the same form as it would have within the comment) or the RP-template with unmarked topic (a similar example from Spanish is given in (22)). Furthermore, if the topic coincides with the primary participant, all three templates can merge into a single sentence structure, as in (70a).

(70) Italian

a. Giovanni ha accettato un lavoro in un'officina meccanica G. he.has accepted a job in a.shop machine-ADJ 'John accepted a job in a machine-shop.'

b. ha accettato un lavoro in un'officina meccanica he.has accepted a job in a.shop machine-ADJ 'He accepted a job in a machine-shop.'

On the one hand, (70a) instantiates the PP-template (i.e., the subject-predicate structure); on the other, it also instantiates the RP-template with unmarked topic, since its comment has the structure of an independent sentence with a highly activated subject referent (cf. (70b)). By the same token, it can be taken to instantiate the SF-template, since the topic expression has the same form as a non-topical subject.

Another type of neutralization is triggered by double topic encoding, whereby different structural templates combined within a single sentence refer to the same topic. The following examples illustrate the combination of RP- and SF-topic encoding in Russian: the pronoun cross-referencing the RP-topic is fronted, so that the comment follows the SF-template with the same topic (see also (24) for a similar example from Italian and (49) for a German example where the RP-template is doubled by the PPtemplate merged with the SF-template). 
(71) Russian (from Internet chats)

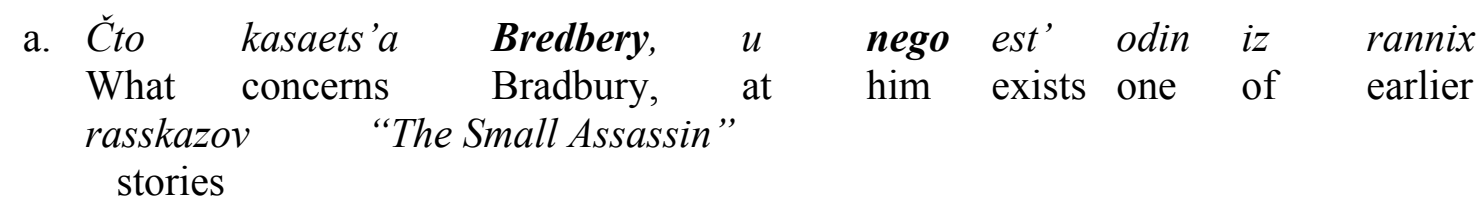

"As for Bradbury, he has an earlier story called "The Small Assassin".

b. Politkorrektnost' ee vzroslyje izobre-li

Political.correctness it:ACC adults:PL.NOM invent-PST.PL

[Children bully one another everywhere.] 'Political correctness, it was invented by adults have invented it.'

The English translations of these examples exemplify a similar combination of RP- and PP-templates pointing to the same topic (see also (48)-(51)).

In European languages, the double topic encoding is optional, that is, the embedded structural template can but need not point to the same topic, presumably depending on whether the sentence has a hyper-topic. It seems, however, that the double topic encoding can also be grammaticalized, so that the PP-template is obligatorily combined with the RP-template for topic encoding. This situation is apparently attested in Dinka, a Western Nilotic language described by Andersen (1991). Declarative clauses in Dinka contain a single preverbal noun phrase, which, according to Andersen's description, encodes the sentence topic. The topic has some properties normally associated with subjects, e.g. the verb must take a special passive-like form if the preverbal NP does not refer to the primary participant (Andersen 1991: 265), cf. (72a) and (72b).

Dinka, Western Nilotic (Andersen 1991: 272)
(72)
a. mòc à-kuàl wén
man D-steal cow
'The man is stealing the cow.'
b. wén à-kućsl môc
cow D-steal:NTS man:GEN
'The man is stealing the cow.'

In the present framework, this would indicate that topicality is encoded by means of the PP-template. On the other hand, the preverbal position is not constrained in terms of its 
role within the comment, e.g. it can correspond to the location of the event being described (73a) and to the possessor (reference point) of a participant of this event (73b).

Dinka, Western Nilotic (Andersen 1991: 281, 284)
(73)
a. ròor à-múuc
$m \hat{o} c$
'The man is shooting in the forest.'
thín
forest D-shoot:AP:NTS man:GEN PRO:LOC
b. màriàal à-théset tiéśch-dè mèth
Marial D-beat:NTS woman-3SG child
'Marial's wife is beating the chid.'

Moreover, if the preverbal NP does not represent the primary participant, the post-verbal part of the sentence can contain a coreferential proform (Andersen 1991:278-283), which indicates that the NP is clause-external. Cross-referencing the topic within the comment conforms to the general constraints on discourse anaphora: it is obligatory for locative topics (as in (73a)) and optional for possessors, instrumentals, and objects (cf. (72b) and (74)).

Dinka, Western Nilotic (Andersen 1991: 276)

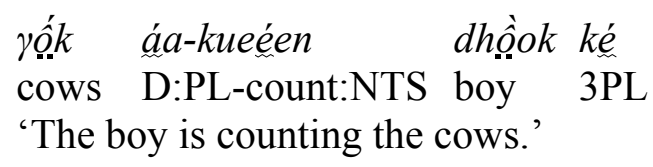

These properties appear to reveal the RP-template; indeed, Andersen's claim is that it is (syntactic) topic, rather than subject. In our view, however, this construction is best described in terms of grammaticalization of double topic encoding: the RP-topic must be simultaneously encoded as a PP-topic (hence the voice-like marking on the verb in sentences where it does not correspond to the primary participant). Thus, the language neutralizes the structural distinction and displays a uniform topic encoding that combines the properties of the RP-template and the PP-template.

The cases of "double" topic encoding and "merged" topic encoding can be consistently distinguished only insofar as the topic can be referred to twice within the sentence. For example, the Italian example in (70) has been described in terms of merging of the RP-template and the PP-template, yet it could as well be described in 
terms of obligatory double encoding, insofar as the use of the PP-template for topic encoding is obligatorily accompanied by the RP-encoding (insofar as the predicate of a subject-topic sentence is inevitably encoded as an independent sentence with a highly activated subject-topic). Note that essentially the same situation is observed in all topicprominent languages, since they are characterized by unrestricted use of zero anaphora (Li \& Thompson 1976: 466-471; Gundel 1988: 239-242). A similar situation arises if the PP-template is merged with the SF-template for topic coinciding with primary participants and these templates cannot point to two different topics within the same sentence (as in German). This means, in effect, that the PP-encoding must be always "doubled" by the SF-encoding; accordingly the SF-template is invoked whenever the PPtemplate is used.

Neutralization of the distinctions between topic-encoding options can have a significant impact on the overall distribution of competing templates in the language. One aspect of this impact was mentioned above: insofar as a specific topic-encoding template occasionally merges with the no-encoding option, its semantic markedness decreases and it is less likely to be used if the topic-comment structure constitutes a salient aspect of the sentence meaning. Alternatively, this can lead to obligatory doubling of topic encoding, whereby the semantically unmarked template is obligatorily accompanied by another topic-encoding template. On the other hand, the processing of a sentence instantiating a pair of merged/doubled topic-encoding templates increases discourse frequency of each template, which, in turn, is likely to promote conventionalization of the otherwise less frequent template and thus decrease its pragmatic markedness.

\subsection{Dimensions of topic-prominence}

The core of our approach to the concept of sentence topic is formed by the idea that the topic-comment structure is an aspect of sentence meaning, i.e. it is determined primarily by what the speaker has to say, rather than by the speaker's assumptions about the listener's state of knowledge and attention. This by no means implies that such assumptions play no role in the choice of topic, yet it is assumed to be no more (and no less) significant than the role of these assumptions in the choice of information to be communicated. For example, a sentence like (3a) (repeated here as (75a) for 
convenience) would hardly be appropriate if the listeners (or, in this case, the readers) were assumed to have no knowledge whatsoever of syntactic theories, the use of schemes in their presentation, and of the role-and-reference grammar and its authors in particular. The same is true for the alternative encoding of the same proposition in (75b), which differs from (75a) in that Val Valin and Foley's schemes (rather than the role of linguistic schemes in general) is perceived as "what the sentence is about".

(75) Russian

$\begin{array}{lllll}\text { a. Takuju } & \text {z} e ~ & \text { illjustrativn-uju funkcij-u } & \text { imej-ut } \\ \text { such } & \text { same } & \text { illustrutive-ACC function-ACC have-PRES.3PL } \\ \text { sxem-y } & \text { R.Van Valin-a } & \text { i W.Foley } \\ \text { scheme-PL.NOM } & \text { R.Van Valin-GEN } & \text { and } & \text { W.Foley }\end{array}$

'The same illustrative role is played by R. Van Valine and W. Foley's schemes.' (A. Kibrik)
b. Sxem-y R.Van Valin-a i W.Foley imej-ut scheme-PL.NOM R.Van Valin-GEN and W.Foley have-PRES.3PL takuju že illjustrativn-uju funkcij-u such-ACC same illustrutive-ACC function-ACC

'R. Van Valin and W. Foley's schemes have the same illustrative function.'

The choice of one sentence structure over the other appears to be guided not by the author's assumptions about his readers state of knowledge, but rather by what he actually wants to say. The structure of (75a) signals that the role of schemes in syntactic theories has the topic status, and the sentence is therefore understood as an additional illustration of the author's general idea about this role. Although the choice of object-initial order is bound to have some impact over processing, the topic status of the object does not amount to a component of processing instruction, but rather belongs to the meaning to be processed.

On the other hand, the choice of one or another construction for encoding of the topic-comment structure is likely to be guided, to a large extent, by the speaker's assumption about the listener's state of knowledge and attention. More specifically, the need for explicit and unambiguous (i.e. semantically marked) encoding of the topiccomment structure is determined by two universal factors, (i) the assumed ability of the listener to infer the topic-comment structure from the context and/or the contents of the sentence, and (ii) the assumed degree of activation of the topic referent by the time of 
utterance. These factors are independent in the sense that if the topic referent is highly activated, the topic-comment structure can still be explicitly encoded if it cannot be inferred:

German
Und das tat er auch
And this did he too

[I have to wake up, he thought.] And he did it too' (Sven Regener, Herr Lehmann. Ein Roman.)

(77) Italian (Berretta 1995: 142)
A: Prendiamo un caffel? take:1PL a coffee
B: No, il caffe1 lo prendiamo a casa No the coffee OBJ.3SG.M take:1PL at home 'Will we have coffee? - No. We'll have coffee at home.'

In both cases, the listener would have been likely to infer, in the absence of the explicit encoding to the contrary, that the topic of the sentence is the primary participant. Accordingly, the speaker needs to resort to the SF-template in (76) and to the "merged" $\mathrm{SF} / \mathrm{RP}$-encoding in (77) in order to signal the intended topic-comment structure.

On the other hand, a low degree of activation of the topic referent would trigger explicit topic encoding even if the topic-comment structure can be inferred. This situation is neatly illustrated by the following Italian conversation:

(78) Italian (field notes)
A: hai preso su la cassetta? have:2SG picked up the cassette
B: eh?
eh
A: la cassetta l'hai presa su? the cassette it:ACC.have:2SG picked up [In the car, before leaving for a holiday] 'A: Have you picked up the (audio)cassette? -- B: Eh? - A: The cassette, have you picked it up?'

The two questions in this example have the same content, and can be assumed to have the same topic (the cassette). The cassette had already been the topic of the conversation preceding this excerpt, so the first speaker (A) initially assumes that this referent is 
sufficiently activated and B will have no problems in identification of the topic and inferring the topic-comment structure of the message. Since B does not understand the question, A apparently changes his assumptions and introduces the topic by means of a clause-external referring expression, which involves explicit encoding of the topiccomment structure.

As described in Section 5.1, the degree of activation of topic-referent is one of the factors that can determine the choice between alternative topic-encoding templates. Apart from this, it can also influence the linear position of the topic expression. Although the most common linear position of structural topics is sentence-initial, they can also occur in the sentence-final position, as exemplified in (79).

a. French (cf. also Lambrecht 1981: 1).

Ils sont fous, ces Romains!

they are mad those Romans

'They're mad, those Romans!'

b. Italian (field notes; casual conversation)

le dicono proprio cosilper dir=le, le notizie them say:3PL really so for tell:INF=them the news

[A: While we were waiting at the tollgate, they said that there was a kilometer-long queue (implying that it wasn't true). B: ] 'They just tell them in order to talk, the news items'

c. German (from 'Die Zeit' 28/3.7.91, p.53)

War eine zu heiße Sache, diese Affäre um

was a too hot matter this affair around

den Pastor

the pastor

'[The pastor, who used to live here, certainly won't check. And the cops won't look into the mail box either. They never hurried in their investigation.] It was too hot a matter, this affair with the pastor.'

The referents of right-detached expressions are usually referred to within the main proposition (as witnessed by boldfaced pronouns in (79a-b) and by the verb agreement in (79c)). The right-detached expression can be encoded for its role in the proposition, i.e. such sentences can instantiate the SF-template, e.g.

(80) Italian (filed notes, casual conversation)

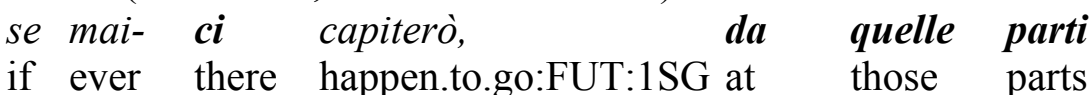


'If I ever happen to go there, in those districts'

Many authors pointed out differences in discourse contexts favouring sentence-initial and sentence-final topics: right-detached referring expressions appear to be limited to referents recoverable from the situation and/or immediate discourse context (e.g. Gundel 1988: 229, Berretta 1995: 150-151; inter alia). According to Givón (1983), a rightdetached NP recalls a discourse topic which is continuous for the speaker, but was introduced at such a distance that the hearer might have lost its track. A further example, drawn from Maltese, illustrates this point.

(81) Maltese (Fischer-Jastrow 1980:288)

$\begin{array}{llll}\text { L-ewwel } & \text { nett } & \text { kien-u } & \text { jagh\#gnu-h } \\ \text { at-first } & \text { completely } & \text { be:PFV-3PL } & \text { knead:IPFV:3PL-3SG.M }\end{array}$

$b^{\prime} \quad$ l-id-ejn, dawn it-tliet $\quad \boldsymbol{x k e j j e r}$

with ART-hand-DU these ART-three sacks

[From a narrative on bread baking] 'At the very first they used to knead it with the hands, these three sacks'

In this example, the third person object suffix - $h$ 'it' refers to the meal gathered from three sacks, which were mentioned in the previous sentence, whereas the right-detached NP recalls the meal by reference to the quantity involved in the kneading operation being described. This seems to suggest that the sentence-final position of topic expression is associated with contexts where the speaker might assume that the referent is sufficiently activated in the listener's mind to be referred to by a pronoun and thus can be viewed as a combination of a topic-encoding template wit the no-encoding option (see (63)). ${ }^{12}$

${ }^{12}$ Such sentence structures can be then associated with the interpersonal or polite function of speech (cf. Aijmer 1989). Berretta (1995: 150-151) points out that in Italian colloquial variety right-dislocation might be losing its marked status, becoming a means for marking positive politeness. Examples such as Lo vuoi, un caffè? 'Would you like it, a coffee?' show construal of the yet unknown topic 'the coffee' as if it were known, a strategy claimed to appealing to the listener's cooperation and to emphasise sharing of knowledge. 
Oversimplifying the matters to some extent, the factors that are likely to trigger semantically marked topic encoding can be subsumed under a single parameter of language-internal variation, which can be referred to as "topic-prominence": in this sense, the degree of topic-prominence of a sentence is determined by the salience of the topiccomment structure in its overall semantic structure and the speaker's assumption about the degree of activation of the topic referent in the listener's mind and context-dependent inferability of the topic-comment structure. As shown in Section 5.1, the RP-template is intrinsically associated with a (relatively) high degree of topic-prominence, the PPtemplate, with the low degree of topic-prominence, and the SF-template occupies an intermediate position on this scale.

To conclude, the RP-template obviously has a privileged status with respect to topic encoding, which manifests itself both in language-internal and in cross-linguistic variation: insofar as the semantic domains of competing templates overlap in a specific language, the RP-template is preferred in topic-prominent contexts; cross-linguistically, the RP-template can serve as the only strategy of topic encoding in topic-prominent languages in Li and Thompson's (1976) sense (see Sections 3.2-3.3). This privileged status is determined, first and foremost, by the fact that both other topic-encoding templates are intrinsically constrained in terms of the role of topic expression in the proposition conveyed by the comment: they cannot be used for encoding of hanging topic. Accordingly, the RP-template consistently wins the competition outlined in Section 5.1 if the relation between the topic and the state of affairs being described cannot be integrated into the propositional structure of the message by morphosyntactic means available in the language. By the same token, the RP-template is the only one that cannot merge with the no-encoding option and thus remains semantically marked in all languages and independently of the relation between the topic referent and the state of affairs being described. On the other hand, due to the combination of factors described in Section 5.1, this template is intrinsically associated with the discourse contexts of topic discontinuity, where neither the topic referent nor the topic-comment structure of the message can be assumed to be inferable, i.e. with the topic-prominent contexts. Consequently, it also consistently wins this competition in the contexts where the need 
for explicit and unambiguous encoding of the topic-comment structure overrides the considerations of structural and pragmatic markedness.

However, the role of the RP-template in the overall system of topic encoding is subject to considerable cross-linguistic variation and can be rather marginal. Although the languages of Europe differ in the degree of conventionalisation of the corresponding $h$ constructions (Geluykens 1989, 1992), they consistently demonstrate that a combination of the SF-template and the PP-template of topic encoding can create a powerful system of topic encoding sufficient for a broad range of discourse contexts.

\section{References}

Aijmer, Karin

1989 "Themes and tails: The discourse functions of dislocated elements". Nordic Journal of Linguistics 12:137-154.

Aissen, Judith.

1999 "External Possessor and Logical Subject in Tz'utujil”, in: Payne, Doris L. and Immanuel Barshi (eds.) External Possession. Amsterdam/Philadelphia: John Benjamins. 167-193.

Barnes, Betsy K.

1985 The pragmatics of left detachment in spoken standard French. Amsterdam: Benjamins (Pragmatics \& Beyond VI:3).

Bernini, Giuliano

1992 The sentence topic in the languages of Europe. EUROTYP Working Papers I/3.

Benincà, Paola, Giampaolo Salvi and Lorenza Frison

1988 "L'ordine degli elementi della frasee le costruzioni marcate", in Lorenzo Renzi (a cura di), Grande grammatica italiana di consultazione. Vol. 1: La frase. I sintagmi nominale e preposizionale. Bologna:Il Mulino, 115225.

Berretta, Monica

1995 "Ordini marcati dei costituenti maggiori di frase: una rassegna". Linguistica e filologia 1: 125-170.

Andersen, Torben

1991 "Subject and topic in Dinka", Studies in Language 15-2. 265-294.

Benincà, Paola \& Giampaolo Salvi \& Lorenza Frison

1988 "L'ordine degli elementi della frasee le costruzioni marcate", in Lorenzo Renzi (a cura di), Grande grammatica italiana di consultazione. Vol. 1: La frase. I sintagmi nominale e preposizionale. Bologna:Il Mulino, 115225.

Bolkestein, A. Machtelt

1993 "15. General ideas of functionalism in syntax", in: Joachim Jacobs \& Arnim von Stechow \& Wolfgang Sternefeld \& Theo Vennemann 
(Hrsg./eds.), Handbücher zur Sprach- und Kommunikationswissenchaft, Band 9.1: Syntax. Berlin: Walter de Gruyter, 339-349.

Büring, Daniel.

1999 "Topic", in: Bosch, Peter and Rob van der Sandt (eds) Focus. Cambridge University Press. 142-165.

Cadiot, Pierre

1992 "Matching syntax and pragmatics: a typology of topics and topic-related constructions in spoken French", Lingiustics 30-1, 57-88.

Chafe, Wallace L.

1976 "Givenness, contrastiveness, definiteness, subjects, topics, and point of view", in Ch.N.Li (ed.) Subject and Topic. Academic Press. New York, San Francisko. London.

1987 "Cognitive constraints on information flow", in Tomlin, Russell S. (ed.), Coherence and Grounding in Discourse, Amsterdam: Benjamins, 21-52.

Chen, Ping

1996 "Pragmatic interpretation of structural topics in Chinese", Journal of Pragmatics 26 (1996), 389-406.

Comrie, Bernard

1981 Language universals and linguistic typology. The University of Chicago

Press.

Cowan, Ron.

1995 "What are discourse principles made of?", in: Downing, Pamela and Michael Noonan (eds.) Word order in discourse. John Benjamins. Amsterdam/ Philadelphia. 29-50.

Croft, William

2000 Explaining language change. An evolutionary approach. Longman Linguistics Libarary.

Daneš, František

1964 "A three-level approach to syntax". Travaux Linguistiques de Prague 1: 225-240. (Traduzione italiana "Per una sintassi a tre livelli", in Sornicola \& Svoboda 1991: 113-133)

Davison, Alice

1984 "Syntactic markedness and the definition of sentence topic", Language 60: 797-846.

Dik, Simon

1989 The theory of Functional Grammar. Part 1: The structure of the clause. Dordrecht: Foris Publications.

Downing, Angela

1997 "Discourse pragmatic functions of the Theme constituent in spoken European Spanish", in: Connonly, John H., Roel M. Vismans, Christopher S. Butler, Richard A. Gatward (eds.) Discourse and Pragmatics in Functional Grammar. Functional Grammar Series 18. Mouton de Gruyter. Berlin - New York. 137-163.

Dryer, Matthew S. 
1995 "Frequency and pragmatically unmarked word order", In: Downing, Pamela and Michael Noonan (eds.) Word order in discourse. John

Eroms, Hans-Werner Benjamins. Amsterdam/ Philadelphia. 105-136.

1986 Funktionale Satzperspektive. (Romanistische Arbeitshefte 31). Tübingen: Niemeyer.

Eschmann, Jürgen

1984 Texte aus dem 'français parlé'. Tübingen:Niemeyer.

Fici Giusti, Francesca \& Lucyna Gebert \& Simonetta Signorini

1991 La lingua russa. Roma: La Nuova Italia Scientifica.

Fischer, Wolfdietrich and Otto Jastrow (eds.)

1980 Handbuch der arabischen Dialekte. (Porta Linguarum Orientalium, Neue

Geluykens, Ronald

Serie XVI). Wiesbaden, Harrassowitz

1989 "The syntactization of interactional processes. Some typological evidence ", in: Kefer-van der Auwera (eds.), 91-103.

1992 From discourse process to grammatical constructions: on left dislocation in English. Amsterdam, Benjamins.

Givón, Talmy

1976 “Topic, pronoun and grammatical agreement”, In Li, Ch.N. (ed.) Subject and Topic. Academic Press. New York, San Francisko. London. 149-188.

1983 (ed.) Topic Continuity in Discourse. A Quantative Cross-Language Study. Amsterdam: Benjamins.

Gundel, Jeanette K.

1988 "Universals of topic-comments structure", In: M.Hammond, E.A.Moravcsik and J.R.Wirth (eds.). Studies in Syntactic Typology. John Benjamins. 209-242.

Gundel, Jeanette K., Nancy Hedberg and Ron Zacharski

1993 "Cognitive status and the form of referring expressions in discourse", Language 69. 274-307.

Hage1ge, Claude

1985 L'homme de paroles. Contribution linguistique aux sciences humaines. Paris:Librairie Arthème Fayard (translated into Italian as L'uomo di

Haiman, John parole. Linguaggio e scienze umane. Torino, Einaudi, 1989).

1983 "Iconic and economic motivation", Language. 59. 781-718.

Harris, Alice C. And Lyle Campbell

1995 Historical syntax in cross-linguistic perspective. Cambridge: Cambridge University Press.

Hawkinson, Annie and Larry Hyman

1975 "Hierarchies of natural topics in Shona", Studies in African Linguistics 5. 147-170.

Hockett, Charles F.

1958 A Course in Modern Linguistics. New York: Macmillan.

Jacobs, Joachim

2001 "The dimensions of topic-comment", Linguistics 39-4. 641-681. 
Kasevič, Vadim B.

1988 Semantika, Syntaksis, Morphologija. (Semantics, Syntax, Morphology.) Moscow. Nauka.

Keenan, Edward L.

1976 "Towards a universal definition of "subject"”, in: Ch.N.Li (ed.) Subject and Topic. Academic Press. New York, San Francisko. London.

1985 "Passive in the world's languages", in: T. Shopen (ed.) Language typology and syntactic description. Cambridge: Cambridge University Press. 243281.

Kiss, Katalin É.

2003 "Discourse-configurationality in the languages of Europe", in A. Siewierska (ed.) Constituent Order in the Languages in Europe. Mouton de Gruyter, Berlin. 681-729.

Kozinskij, Iosif S. and Natalja K.Sokolovskaja

1984 "O sootnoshenii aktual'nogo i sintaksichskogo chlenenija v sinhronii i diahronii" (On the relation between functional and syntactic sentence structure in sinchrony and diachrony), in: Solncev, V.M. (ed.) Vostochnoje jazykoznanije: Grammaticheskoje i aktual'noje chlenenije predlozhenija. Nauka. Moscow.

Kratzer, Angelika.

1995 "Stage-level and individual-level predicates", In G.N. Carlson \& F. J Pelletier (eds), The Generic Book. Chicago: The University of Chicago Press. 125-175

Kumashiro, Toshiyuki and Ronald W. Langacker

2003 "Double-subject and complex-predicate constructions", Cognitive Linguistics 14-1. 1-45.

Kuno, Susumo

1987 Functional Syntax. The University of Chicago Press, Chicago

Lambrecht, Knud

1981 Topic, Antitopic and Verb Agreement in Non-Standard French, Amsterdam: Benjamins.

1994 Information structure and sentence form. Cambridge studies in linguistics. Cambridge University Press.

Langacker, Ronald W.

1990 Concept, image and symbol: the cognitive basis of grammar. Mouton de Gruyter. Berlin and NewYork.

1993 Reference-point constructions. In: Cognitive linguistics, 4-1. 1-38.

Li, Charles N., and Sandra A. Thompson.

1976 "Subject and Topic: A New Typology of Languages", In: Li, Charles N.

(ed.) Subject and Topic. Academic Press. New York, San Francisko. London. 457-490.

Lockwood, W. B.

1995 Lehrbuch der modernen jiddischen Sprache. Mit ausgewählten Lesestücken. Hamburg: Buske.

Lötscher, Andreas

1992 "The pragmatics of nonreferential topics in German (and other languages)", Linguistics 30-1: 23-145. 
Maienborn, Claudia

1996 Situation und Lokation: Die Bedeutung lokaler Adjunkte von Verbalprojektionen. Tübingen: Stauffernburg.

Mathesius, Vil'em

1929 Zur Satzperspektive im modernen Englisch. Archiv für das Studium der modernen Sprachen und Literaturen 155, 200-210.

Miller, Jim

1992 "Null subjects and direct objects in Russian: remarks on topic continuity in Russian and English". In: Giuliano Bernini and David Ricca (eds.), Topics. EUROTYP Working Papers I/2. 91-117.

Nedjalkov, Vladimir P.

1977 "Possessivnostj i inkorporacija v chukotskom jazyke (inkorporacija podlezhaschego)" (Possessivity and incorporation in Chukchee (subject incorporation)) In: Problemy lingvisticeskoj tipologii i structury jazyka. Nauka. Leningrad. 108-137.

O’ Siadhail, Mícheál

1988 Learning Irish. An Introductory Self-Tutor. New Haven:Yale University

Press.

Parshin, Pavel B.

1983 “Tema i topic: k sootnosheniju poniatij". In: Voprosy vostochnogho jazykoznanija. Nauka. Moscow.

Polinsky, Maria

1999 Review of Lambrecht 1994. Language 75. 567-582

Prince, Ellen F.

1981 "Toward a taxonomy of given-new information", in: Peter Cole (ed.). Radical pragmatics. (Syntax and semantics), New: York:Academic Press, 213-255.

Reinhart, Tanya

1982 "Pragmatics and linguistics: An analysis of sentence topics", Philosophica 27: 53-94.

Tomlin, Russel S.

1995 "Focal attention, voice, and word order: an experimental, cross-linguistic study", In P. Downing \& M. Noonan (Eds.), Word order in discourse. Amsterdam: John Benjamins. 517-554

Sasse, Hans-Jürgen

1987 "The thetic/categorical distinction revisited", Linguistics. 25/3:511-580

Shibatani, Masayoshi

1990 The languages of Japan. Cambridge University Press.

1991 "Grammaticization of topic into subject", in: Traugott, Elisabeth Closs \& Bernd Heine (eds.) Approaches to grammaticalization. Vol. II: Focus on types of grammatical markers. Amsterdam: Benjamins. 93-133.

Sornicola, Rosanna abd Aleš Svoboda (eds.)

1991 Il campo di tensione. La sintassi della Scuola di Praga. Napoli: Liguori.

Strawson, P.F.

1964 "Identifying reference and truth values". Theoria, XXX, 1964, p.96-118.

Vallduví, Enric 
1995 "Structural properties of information packaging in Catalan", in: Kiss, Katalin É. (ed.) Discourse configurational langagues. Oxford University Press. New York. Oxford. 122-152.

van Valin Robert D. and William A.Foley

1980 "Role and reference grammar", in: E.Moravcsik (ed.). Current approaches to syntax. Syntax and Semantics, vol.13, Academic Press. New York. 329352.

1985 "Information packaging in the clause", in: T.Shopen (ed.) Language typology and syntactic description. Cambridge: Cambridge University Press. 282-364. 